\title{
The representation of ontological category concepts as affected by healthy aging: Normative data and theoretical implications
}

\author{
LORNA I. MORROW and M. FRANCES DUFFY \\ University of Glasgow, Glasgow, Scotland
}

\begin{abstract}
Attributes associated with concept representations, such as familiarity, typicality, and age of acquisition, have been shown to be important influences on lexical-semantic processing. In most previous studies of healthy and pathological aging, these attributes are not equated for younger and older adults separately on the stimuli used. In this study, normative data were collected to test whether there exist any age differences in these attributes. The results demonstrate that the ratings given by younger and older adults on natural and manmade category items correlated positively. However, age differences were also apparent, whereby older adults provided higher ratings overall than younger adults. Suggestions and hypotheses are presented to explain this pattern of age differences, which relate to how category concepts may be represented by healthy younger and older adults. Also, the possible implications for these differential age ratings on lexical-semantic processing are discussed. The age differences apparent in this study demonstrate the need to consider age-appropriate normative ratings in the selection of stimuli for use in lexical-semantic processing studies of aging, and the normative data presented provide a means of equating category stimuli. The complete list of all the means is available at www.psychonomic.org/archive.
\end{abstract}

In recent years, there has been considerable experimental investigation dedicated to cognitive processing in healthy and pathological aging and neuropsychological studies. Particular topics of investigation have included lexical processing (see, e.g., Myerson, Hale, Chen, \& Lawrence, 1997), word priming (e.g., Laver, 2000) and inhibition (negative priming; e.g., Friederici, Schriefers, \& Lindenberger, 1998), and semantic category processing. Interest in the area of category processing was fueled by reports that certain patterns of brain atrophy can selectively damage the processing of specific categories of information. In particular, selective deficits in recognizing and identifying natural items (e.g., animals, vegetables, etc.) relative to manmade items (e.g., vehicles, tools, etc.) have been reported (e.g., Warrington \& Shallice, 1984) after widespread bilateral damage. In fewer cases, the opposite pattern of a deficit for manmade items has also been found (e.g., Warrington \& McCarthy, 1983, 1987), suggesting a double dissociation (see Saffran \& Sholl, 1999, for a review).

\footnotetext{
The authors are grateful to A. Mike Burton, Anthony J. Sanford, Simon C. Garrod, and Linda M. Moxey for helpful comments on earlier versions of the manuscript; to Sheena MacDonald for her assistance with data entry; and to the participants. The authors are also extremely grateful to Philip A. Allen and an anonymous reviewer for invaluable suggestions. This study was supported by a Psychology Benefactor Scholarship awarded to the first author by the Department of Psychology, University of Glasgow. Correspondence should be addressed to L. I. Morrow, Department of Psychology, University of Glasgow, 58 Hillhead St., Glasgow, G12 8QB Scotland (e-mail: 1.morrow@psy.gla.ac.uk).
}

In almost all of the more recent studies of category processing, the natural and manmade stimuli have been carefully equated on measures of concept and/or word knowledge, such as frequency of occurrence. This is crucial, given that, otherwise, investigations of the main hypotheses of how such category deficits may arise (e.g., according to selective damage to certain types of features, or differences in the way these categories are represented, etc.) would be seriously confounded by the experimental stimuli. For example, in the real world, living, natural things are generally less frequent and less familiar than nonliving, manmade things. Thus, in tests of semantic processing, if natural and manmade stimuli are not controlled for frequency of occurrence or familiarity, then it may be that the presence, or magnitude, of category-specific deficits found is simply a by-product of the stimuli (see, e.g., Humphreys \& Riddoch, 1987). The importance of controlling category stimuli has been demonstrated in studies in which the natural category deficit evidenced for some patients disappeared when stimuli were sufficiently controlled (e.g., Parkin \& Stewart, 1993); however, there have been many reports of category effects even when additional stimuli selection measures were employed (e.g., Moss, Tyler, \& Jennings, 1997).

Although stimuli are carefully and painstakingly controlled between categories in such studies, the same measures are not taken to control stimuli between age cohorts. Thus, stimuli for use in studies involving older adults, whether healthy or with neuropsychological impairments, are generally selected from norms collected from younger adults, on the basis of the assumption that the items will 
be equally salient to both age groups. This means that there may exist inequalities in the saliency, and so forth, of the stimuli between older and younger adults in studies of processing changes with healthy aging, and there may also be inequalities between age cohorts and categories for studies of category-specific deficits in neuropsychological patients.

Perhaps the assumption that norms collected from younger adults will be sufficient for use with older cohorts is at least partly due to the fact that many early comparisons of (predominantly) association data between younger and older adults (e.g., Bowles, Williams, \& Poon, 1983; Brown \& Mitchell, 1991; Howard, 1979; Perlmutter \& Mitchell, 1982; Scialfa \& Margolis, 1986) reported few age differences. However, in contrast to this, an association study by Hirsh and Tree (2001) provided evidence that, although the structure of the relationships within semantic memory was not affected with aging, the content differed considerably between age groups.

Similarly, category norms, whereby participants have to generate members of categories using recall processes, have also been collected from different age groups, with differing results. Howard (1980) reported more similarities than differences between age groups and argued that norms collected from younger people were appropriate for use with older age groups for categories with a high level of age stability. In contrast, from the results of a slightly modified category norms task, Brosseau and Cohen (1996) presented evidence that the representation of semantic categories differs between age groups, and thus stressed the importance of controlling for age differences in semantic category representations.

Finally, further evidence that the representations of concepts in semantic memory are modified with age, in terms of how related concepts are, has been reported by Conley and Burgess (2000a, 2000b).

In light of this evidence that words and concepts may indeed be represented differently between age groups, it would seem that such differences may also extend to the representation of ontological category concepts. Indeed, it needs to be ascertained whether the factors that influence lexical-semantic processing also differ between age groups. On the basis of the evidence described, it is hypothesized that such age differences in ontological category representations do exist; but, of course, such a hypothesis needs to be explored empirically. This issue is important, given that, unless these factors are taken into account and circumvented, they may have a confounding influence on studies attempting to explore category processing in samples of younger and healthy older adults and of neuropsychological patients. Perhaps more importantly still, determining whether there are age differences in the representation of semantic concepts has theoretical implications for the issue of cognitive changes with healthy aging. In order to interpret any age differences in semantic processing reported in empirical investigations (e.g., slower performance of older adults), it must be ascertained whether the differences are due to poorer, less salient semantic representations, or slower processing speeds, associated with healthy aging (or because the stimuli used are not appropriate for the different cohorts). Collecting normative data is one way of measuring the saliency of semantic concepts as represented in the brain. Should the data provide no evidence of age differences in the representation of concepts, then this allows the assumption that any differential effects of age in semantic processing studies are the result of changes to processing, not changes in the semantic store. Furthermore, this would merit the use of norms collected from younger adults to be used in studies of healthy or pathological aging, since these norms should reflect the saliency of representations for both age groups. Alternatively, if the norms collected here provide evidence for changes in the semantic representations of concepts, then this would provide valuable insights into the changes that occur in the semantic store with healthy aging and suggest that such changes contribute to some degree to the overall age differences (response time, accuracy, etc.) in performance. With the emergence of such age differences, normative data must be made available to allow investigators to equate stimuli between age cohorts in studies of cognitive processing.

There exist some measures of word attributes, such as the frequency ratings of Francis and Kučera (1982) that were collected from "objective" sources (specifically, the occurrence of words in written media), which may be equally applicable to different age groups. This method of obtaining frequency measures is valuable for assessing how often the written words are read. Unfortunately, however, these norms do not take account of how often the objects are encountered in everyday life, nor do they reflect the frequency with which the objects are processed in semantic memory, other than that which is confined to the processing of their written form. Therefore, frequency ratings that reflect the total exposure that people have to objects, in any form, might be a more accurate measure. ${ }^{1}$

In addition to frequency, other measures of word attributes were collected in the present study, because, even though ratings of frequency of occurrence are equated in a particular stimuli list, it is possible that the stimuli might still suffer from category inequalities in other measures that have not been addressed, to the detriment of a particular category. Controlling the stimuli on different ratings may better eradicate stimuli confounds. For example, in addition to ratings of frequency of occurrence, familiarity ratings might be beneficial for excluding stimuli confounds. Although it could possibly be predicted that frequency of exposure to an object should mean that people become more familiar with it to some extent, the relationship between these measures cannot be perfect, since other factors must surely intervene.

Even though word stimuli are often used to access semantic memory, this does not mean that visual information about the object is not accessed during this process. Kellenbach, Wijers, and Mulder (2000) reported evidence of automatic priming of words related only by visual characteristics. Thus, even when word stimuli, rather than pic- 
ture stimuli, are processed, differential attributes of visual information (e.g., the complexity of the stored representation) may indeed affect the pattern of semantic category differences. For this reason, it was deemed important to collect ratings of the visual complexity of an item, as well as ratings of how imageable an item is. These ratings were generated from the participants' mental representations of these objects, rather than on any presented image of the object, in order to access information about the visual characteristics represented in semantic memory.

Typicality ratings also seem to be important in lexicalsemantic processing, affecting accuracy in categorization tasks (in both younger and older adults; Myerson et al., 1997), speed of pronunciation (Allen, Goldstein, Madden, \& Mitchell, 1997), and priming (Hines, Czerwinski, Sawyer, \& Dwyer, 1986). Typicality may also interfere with category processing, since the higher degree of featural similarity of natural category exemplars to their coordinate members may result in natural exemplars being more representative, or typical, of their categories than manmade items.

Similarly, evidence has been reported that the age of acquisition affects both speed and accuracy of lexical and semantic processing in younger and older adults (see, e.g., Morrison, Hirsh, Chappell, \& Ellis, 2002). Indeed, the age at which information was acquired may have some bearing on the robustness of the representation in semantic memory (see Rochford \& Williams, 1962, for a study of aphasic patients), as well as how much is known about the concept and its relation to other concepts. Thus, any cohort or category differences in age of acquisition may affect performance on psychological studies.

To summarize, in the present study, data were assembled from a comprehensive list of concrete category nouns on a number of measures of concept knowledge. In particular, the measures for which ratings were collected were typicality, frequency, familiarity, imageability, visual complexity, and age of acquisition. Rather than collecting objective measurements of frequency, we obtained ratings as a subjective measure of how often the participants encountered the concept, either in its real form or as a word or picture. Similarly, we collected age-of-acquisition ratings from subjective recollections (see Morrison, Chappell, \& Ellis, 1997, for evidence that subjective age of acquisition ratings are valid and reliable). The exhaustive number of category exemplars included in this study makes it possible to explore whether differences do indeed exist in how these semantic categories are represented and processed by younger and older adults. This provided valuable insights regarding the changes that occur in the brain as a function of healthy aging - in particular, whether age differences in semantic processing are affected by age differences in the semantic store or other cognitive processes that are involved in performance. Thus, to this end, the present study furthered the work of Howard (1980) and Brosseau and Cohen (1996) in exploring category representations, but without the same dependence on episodic memory for recall of category members, which could be difficult for older adults (see Light, 2000). Furthermore, if age differences were demonstrated, these normative data would provide an invaluable tool to better equate natural and manmade item category exemplars using age-appropriate norms for older neuropsychological patients in the investigation of category-specific deficits.

\section{METHOD}

\section{Participants}

Fifty-four younger adults (age range $=16-28$ years, mean age $=$ 21.3 years, $S D=2.7$ years; mean years of education $=15.3, S D=$ 2.4 years), who volunteered in response to advertisements around the campus of the University of Glasgow, participated in this study. Thirty-four of the participants were female, and 20 were male. However, 1 younger male participant failed to complete the entire questionnaire, and so the data from this participant were excluded.

Fifty-four older adults (age range $=62-85$ years, mean age $=$ 71.1 years, $S D=4.8$ years; mean years of education $=14.0, S D=$ 3.4 years) also participated. These participants volunteered in response to advertisements in local newspapers. They lived independently, traveled to the University of Glasgow unaided, and considered themselves healthy for their age. The average estimated IQ of this group according to the National Adult Reading Test (NART; Nelson, 1982) was 120.95 (range $=106-127)$. The group consisted of 32 females and 22 males.

All of the participants were native speakers of British English, with English as their first language, and had lived most of their lives in Great Britain or the Republic of Ireland.

\section{Stimuli}

The stimuli comprised 888 noun words: 444 from seven natural categories (animals, birds, flowers, fruit, insects, trees, and vegetables), and 444 from seven manmade item categories (clothing, cutlery, musical instruments, jewelry, furniture, tools, and transport).

The items were selected from the responses of 20 younger and 20 older adults on a category fluency task. The participants were asked to report verbally as many items as possible that belonged to a given category, and they were given $1 \mathrm{~min}$ for each category. Each participant was asked to generate responses to all 14 categories. Responses were recorded on tape and later transcribed by the experimenter. Items were chosen for inclusion in the questionnaire if generated by more than 1 participant. Since items were chosen for the norm study in this way, some of the exemplars generated by the participants were particularly uncharacteristic of the category to which they were given in response (e.g., cod in the animals category, surfboard in the vehicles category). However, these items were not excluded from the questionnaire. It was expected that the unrepresentative nature of these items would affect only their typicality ratings and none of the other measurements. In addition, the items generated from the category fluency task were compared with those from the category norms collected by Battig and Montague (1969). Any items that had been omitted from the fluency data that were frequently produced in response to the categories as reported by Battig and Montague were included.

The items were arranged in pages according to one of two randomized sequences. The pages were then shuffled into a random order for each participant and organized into booklets.

\section{Procedure}

The participants were asked to rate each of the words in the booklet on six measures: typicality, familiarity, frequency, visual complexity, imageability, and age of acquisition. Each of these terms was defined, as follows, and an example item was given with some dialogue to help the participants understand the scale and each of the measures. Typicality was defined as how representative the item 
was of the category to which it belonged. For each item, the assigned category was also presented (e.g., WATCH [jewelry]). For familiarity, the participants were asked how acquainted they were with the item (i.e., how much knowledge they had about the item). The measure of frequency was subjective, whereby the participants were asked to consider how often they encountered the item in any form, considering their exposure to the real item, pictures of the item, and the written word. For visual complexity, the participants were asked to rate how detailed or intricate the item was in real life; for imageability, they were asked to rate how easy it was to visualize the item. Finally, the age of acquisition measure was used to determine approximately how old the participants were when they first learned the word.

Responses for typicality, familiarity, frequency, visual complexity, and imageability were to be marked on a 7-point Likert scale, where 1 signified not at all, 4 represented moderately, and 7 indicated extremely. For the age of acquisition measurement, the participants could choose from the following alternatives: $0-2$ years, 3-4 years, 5-6 years, 7-8 years, 9-10 years, $11-12$ years, and $13+$ years. The participants were asked to indicate their response by circling the corresponding numbers on the scale. If any of the words were completely unknown to the participants, they were instructed to mark it with a cross and to leave the measures blank. Each of the exemplar words were presented in uppercase, with its category label in lowercase on the right.

After the participants read the instructions page and followed the example through, the instructions were then presented again verbally, and the participants were free to ask any questions that they had, to ensure they had correctly understood what was required.

\section{Data Handling}

All of the values were entered into a database. Items that had been omitted by the participants were also omitted in the database, were not replaced, and were not examined further. The number of times an item was omitted was not more than five across participants in each group. When items were unknown, the number of younger and older participants who did not know the word was counted and recorded as a percentage. ${ }^{2}$ The means for each of the items on each of the measures were then calculated, and the standard deviations obtained.

For the sake of ease of statistical comparison, the seven categories of age ranges used by participants when rating age of acquisition were numbered $1-7$, as for the other categories, according to the following: 1 corresponded to $0-2$ years, 2 corresponded to $3-4$ years, 3 corresponded to 5-6 years, 4 corresponded to 7-8 years, 5 corresponded to 9-10 years, 6 corresponded to 11-12 years, and 7 corresponded to $13+$ years.

\section{RESULTS}

A list of all the means (and $S D$ s) for each of the ratings for each item in the Animal category is presented in Appendix A for younger adults and in Appendix B for older adults. The descriptive data for each of the items (collapsed across participants) are presented in Table 1, and the complete list of all the means can be found on (and downloaded for use from) the Psychonomic Society's Archive of Norms, Stimuli, and Data (www.psychonomic .org/archive), as well as the first author's Web site (www .psy.gla.ac.uk/ lorna/norms).

Correlations were obtained, using Pearson's $r$ test, between each of the seven measures for the 888 category nouns from younger and older adults separately (see Table 2 for the correlation matrices). The patterns of correlations were similar for both age groups. In particular, significant positive correlations were demonstrated between typicality, familiarity, frequency, and imageability.

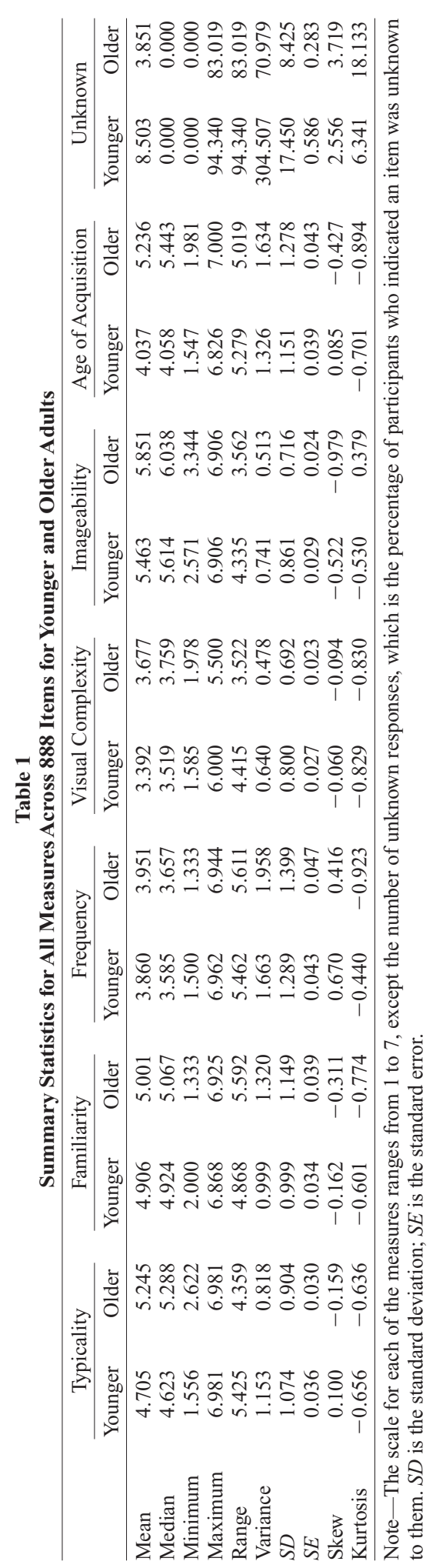


Table 2

Correlations Among Ratings for 888 Nouns From Younger and Older Adults (Within Age Groups)

\begin{tabular}{llccccc}
\hline & & & & Visual \\
& Age Group & Typicality & Familiarity & Frequency & Complexity & Imageability \\
\hline Familiarity & Younger & $.629^{* * *}$ & & & & \\
& Older & $.810^{* * *}$ & & & & \\
Frequency & Younger & $.617^{* * *}$ & $.935^{* * *}$ & & & \\
& Older & $.799^{* * *}$ & $.936^{* * *}$ & & & \\
Visual Complexity & Younger & -.027 & $-.330^{* * *}$ & $-.349^{* * *}$ & & \\
& Older & $.138^{* * *}$ & $-.079^{* *}$ & $-.092^{* *}$ & & \\
Imageability & Younger & $.508^{* * *}$ & $.938^{* * *}$ & $.847^{* * *}$ & $-.343^{* * *}$ & \\
\multirow{2}{*}{ Age of Acquisition } & Older & $.690^{* * *}$ & $.908^{* * *}$ & $.795^{* * *}$ & -.049 & \\
& Younger & $-.524^{* * *}$ & $-.856^{* * *}$ & $-.777^{* * *}$ & $.190^{* * *}$ & $-.826^{* * *}$ \\
& Older & $-.622^{* * *}$ & $-.746^{* * *}$ & $-.676^{* * *}$ & .006 & $-.697^{* * *}$ \\
\hline${ }^{*} p<.05 .{ }^{* *} p<.01$. & ${ }^{* * *} p<.001$. & & & & &
\end{tabular}

Age of acquisition correlated negatively with these measures. Although visual complexity correlated negatively with familiarity and frequency for both age groups, differences between age groups emerged for correlations involving visual complexity and the other measures. For younger adults, visual complexity correlated negatively with imageability and correlated positively with age of acquisition. The trend toward a negative relationship between visual complexity and typicality was not significant. For older adults, the correlations between visual complexity and imageability and between visual complexity and age of acquisition were not significant, and the positive correlation between visual complexity and typicality was significant.

When correlation analyses between measures were carried out for natural and manmade items separately for each age group, the same patterns emerged (see Table 3). Excluding visual complexity from the description of the results for a moment, the specific patterns that emerged for each age group and category were those of positive correlations between typicality, familiarity, frequency, and imageability; age of acquisition correlated negatively with these measures. ${ }^{3}$ Again, the pattern of correlations involving visual complexity were different between age groups, with some differences also emerging between ontological categories within age groups. For younger adults, visual complexity correlated negatively with familiarity, frequency, and imageability and correlated positively with age of acquisition for both natural and manmade item categories. However, visual complexity also correlated negatively with typicality for manmade items only; the positive correlation for natural items was not significant. For older adults, the positive correlation between visual complexity and typicality was significant for both categories; the correlations with familiarity, imageability, and age of acquisition were not significant. Furthermore, although frequency correlated negatively with visual complexity for natural items, this correlation was not significant for manmade items.

Table 3

Correlations Among Ratings for 444 Natural and 444 Manmade Items From Younger and Older Adults (Within Age Groups)

\begin{tabular}{|c|c|c|c|c|c|c|c|}
\hline & Age Group & Item & Typicality & Familiarity & Frequency & $\begin{array}{c}\text { Visual } \\
\text { Complexity }\end{array}$ & Imageability \\
\hline \multirow[t]{4}{*}{ Familiarity } & Younger & Natural & $.722^{* * *}$ & & & & \\
\hline & & Manmade & $.635^{* * *}$ & & & & \\
\hline & Older & Natural & $.834^{* * *}$ & & & & \\
\hline & & Manmade & $.835^{* * *}$ & & & & \\
\hline \multirow[t]{4}{*}{ Frequency } & Younger & Natural & $.700^{* * *}$ & $.939^{* * *}$ & & & \\
\hline & & Manmade & $.641^{* * *}$ & $.936^{* * *}$ & & & \\
\hline & Older & Natural & $.790^{* * *}$ & $.950^{* * *}$ & & & \\
\hline & & Manmade & $.837^{* * *}$ & $.925^{* * *}$ & & & \\
\hline \multirow[t]{4}{*}{ Visual Complexity } & Younger & Natural & .032 & $-.261^{* * *}$ & $-.389^{* * *}$ & & \\
\hline & & Manmade & $-.116^{*}$ & $-.320^{* * *}$ & $-.255^{* * *}$ & & \\
\hline & Older & Natural & $.181^{* * *}$ & -.032 & $-.122^{*}$ & & \\
\hline & & Manmade & $.109^{*}$ & -.044 & -.009 & & \\
\hline \multirow[t]{4}{*}{ Imageability } & Younger & Natural & $.638^{* * *}$ & $.945^{* * *}$ & $.860^{* * *}$ & $-.241^{* * *}$ & \\
\hline & & Manmade & $.515^{* * *}$ & $.935^{* * *}$ & $.848^{* * *}$ & $-.354^{* * *}$ & \\
\hline & Older & Natural & $.764^{* * *}$ & $.911^{* * *}$ & $.808^{* * *}$ & .049 & \\
\hline & & Manmade & $.700^{* * *}$ & $.904^{* * *}$ & $.787^{* * *}$ & -.032 & \\
\hline \multirow[t]{4}{*}{ Age of Acquisition } & Younger & Natural & $-.681^{* * *}$ & $-.884^{* * *}$ & $-.789^{* * *}$ & $.102^{*}$ & $-.874^{* * *}$ \\
\hline & & Manmade & $-.432^{* * *}$ & $-.848^{* * *}$ & $-.782^{* * *}$ & $.237^{* * *}$ & $-.833^{* * *}$ \\
\hline & Older & Natural & $-.720^{* * *}$ & $-.791^{* * *}$ & $-.697^{* * *}$ & -.067 & $-.778^{* * *}$ \\
\hline & & Manmade & $-.551^{* * *}$ & $-.732^{* * *}$ & $-.669^{* * *}$ & .043 & $-.679^{* * *}$ \\
\hline
\end{tabular}

${ }^{*} p<.05 . \quad{ }^{* * *} p<.001$. 
Tests were carried out to examine whether or not the correlation coefficients for visual complexity from the younger and older adults differed significantly (see Fisher, 1921; such comparisons between age groups on the other measures were not carried out, since there were no similar age differences in the correlations). This revealed that all of the differences in correlation were significant between age groups, for both natural and artifact categories ( $p<$ .01 , except for the comparison of visual complexity and age of acquisition for natural items, where $p<.05$ ).

Comparisons between age groups were conducted using Pearson's $r$ correlation tests and $t$ tests for related samples. These results demonstrated that the ratings given by younger and older adults correlated positively and strongly on all of the measures across all of the items (the means, correlation coefficients, and $t$ values are presented in Table 4), even when separate correlations were carried out for natural and manmade items separately (see Table 5). However, $t$ tests also demonstrated that, when all 888 items were considered, the ratings for older adults were significantly higher than for younger adults on measures of typicality, familiarity, frequency, visual complexity, imageability, and age of acquisition. When the $t$ tests were carried out separately for the ontological categories, the same pattern emerged, except that familiarity ratings for natural items and frequency ratings for manmade items did not differ between groups. In all analyses, younger adults knew significantly fewer of the items than did older adults.

The correlation and $t$-test comparisons between age groups for the 14 categories are summarized in Table 6 . Although the general pattern was that the ratings for older adults were higher than those for younger adults, this was not the case for all measures of all of the categories. Indeed, in some cases, the ratings were significantly higher for younger adults, as in the case of familiarity with musical instruments and animals.

Finally, when $t$ tests for unrelated groups were conducted to explore differences between categories, the pattern of results was almost identical for younger and older adults (see Table 7). Natural items were rated by both age groups as less familiar, less frequent, and less imageable than manmade items, but more visually complex. Natural items were rated as being more typical than manmade items of their superordinate categories and indeed acquired at a later age by younger participants only (similar trends in the same direction for older adults did not reach significance). Finally, it seems that fewer natural items than manmade items were known by older adults, whereas this pattern was not significant for younger adults.

\section{DISCUSSION}

The present study details the collection of a comprehensive corpus of norms for natural and manmade item category exemplars. Ratings of typicality, frequency, familiarity, visual complexity, imageability, and age of acquisition were collected from both younger and older adults. The inclusion of these six measures provides the information needed to perform statistical comparisons of category ratings within age groups and between age groups, to ascertain how the representations of these ontological categories are affected by healthy aging. Such data have implications for the interpretation of results showing age differences in performance on semantic tasks, with regard to whether these differences are affected by age-related changes in the semantic store itself or are due solely to changes in cognitive processing. If differences between age groups emerge, this also has implications for studies of semantic category processing with neuropsychological patients who belong to an older age cohort, since the stimuli used may not be equated on norms that are appropriate for that age group, having a potential confounding effect on the results. These normative data should then provide a particularly invaluable tool for the selection of category exemplars for use with older adults.

\section{Category Differences}

Overall, manmade items are rated as being more frequently encountered, having more knowledge associated with them and being more imageable than natural items for both groups. However, as would be predicted, natural items were deemed to be more typical of their superordinate categories than manmade items (although this reached significance for the younger adults only), presumably reflecting denser and more defined category structures for both age groups. Natural items were also rated by both age groups as being more visually complex than were manmade items. As discussed previously, such factors as typicality and visual complexity may influence word processing. Indeed, on the basis of these comparisons between categories, it is interesting to note that the entire category of natural items, or even any given selection, would be predicted to be more difficult to process than manmade items for both age groups. The differences reported here between categories therefore further dem-

Table 4

Results of Correlations and $\boldsymbol{t}$ Tests Between Younger and Older Adults' Ratings for All 888 Items

\begin{tabular}{|c|c|c|c|c|c|c|c|}
\hline & Typicality & Familiarity & Frequency & $\begin{array}{c}\text { Visual } \\
\text { Complexity }\end{array}$ & Imageability & $\begin{array}{c}\text { Age of } \\
\text { Acquisition }\end{array}$ & Unknown \\
\hline \multicolumn{8}{|l|}{$M$} \\
\hline Younger & 4.705 & 4.906 & 3.860 & 3.392 & 5.463 & 4.037 & 8.503 \\
\hline Older & 5.245 & 5.001 & 3.951 & 3.677 & 5.851 & 5.236 & 3.851 \\
\hline$r$ & $.837^{* * *}$ & $.781^{* * *}$ & $.862^{* * *}$ & $.876^{* * *}$ & $.797^{* * *}$ & $.761^{* * *}$ & $.644^{* * *}$ \\
\hline$t$ & $27.374^{* * *}$ & $3.882^{* * *}$ & $3.788^{* * *}$ & $21.970^{* * *}$ & $22.211^{* * *}$ & $42.145^{* * *}$ & $-10.163^{* * *}$ \\
\hline
\end{tabular}




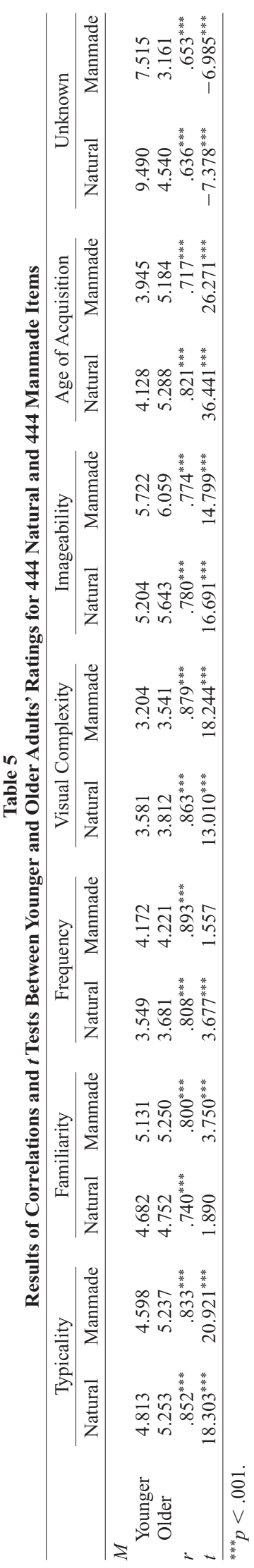

onstrate the importance of equating category information on all of these attributes in order to obtain an accurate picture of how these categories are represented or processed in healthy and in neuropsychological samples. Furthermore, the normative data presented in this study provide a means of equating the stimuli on six different measures of concept knowledge.

\section{Age Group Comparisons}

Correlations within age groups highlighted many similarities. In particular, consistent positive correlations were demonstrated between typicality, familiarity, frequency, and imageability, which were robust for both ontological categories separately and when collapsed together. Regarding the latter three initially, it is easy to understand why, as the frequency with which someone encounters an object increases, their knowledge of the characteristics (visual and nonvisual) of this concept should also increase (as indicated by the ratings of imageability and familiarity). Regarding the relationship between these variables and typicality, it seems that as exposure to and knowledge of an object increases, so too does the extent to which this object is regarded as typical of the category to which it belongs (see Johnson, 2001; this issue will be further discussed below).

Another robust effect for both age groups was the pattern of negative correlations between age of acquisition with typicality, familiarity, frequency, and imageability. This presumably reflects the fact that items that were acquired at a later age are not frequently encountered, nor do they have much knowledge associated with them.

The pattern of correlations involving visual complexity appeared to be inconsistent between age groups and ontological categories. This indicates that, in stark contrast to the measures discussed above, visual complexity does not correlate with any of the other measures reliably.

Comparisons between age groups on each of the measures demonstrated strong, consistent positive correlations. This shows that the different age groups responded reliably and agreed overall on the patterns of ratings given. However, interestingly, the results also demonstrated that older adults provided larger ratings than younger adults. This might have been the result of a response bias, whereby the older adults consistently provided larger ratings than did the younger adults across all concepts, for reasons unrelated to the stimuli presented. However, closer inspection of the data indicated that it is not always the case that older adults provide larger ratings. For example, familiarity and frequency ratings for musical instruments were significantly larger for younger adults than for older adults; for jewelry, there were no differences in the ratings given between age groups on typicality, familiarity, or imageability, whereas the ratings given for frequency were significantly higher for younger adults (see Table 6 for many more such instances).

Interestingly, there is also some evidence that the higher ratings obtained with increased age in this study may actually reflect a developmental trend, at least for some measures. Some studies that have compared the ratings given 
by adults and children have demonstrated higher ratings from the adults than from the children on the measures of typicality (Bjorklund, Thompson, \& Ornstein, 1983), familiarity (Berman, Friedman, Hamberger, \& Snodgrass, 1989; Cycowicz, Friedman, Rothstein, \& Snodgrass, 1997; Pompéia, Miranda, \& Bueno, 2001), and visual complexity (Berman et al., 1989; Pompéia et al., 2001). It is unclear what factor, other than actual differences in the representations of concepts between age groups, could have mediated these consistent patterns of larger ratings with increasing age from childhood through senior years. Indeed, it seems highly unlikely that a confounding response bias in all of these studies could have caused the significant age differences in ratings. Therefore, if the higher ratings from older adults are not the consequence of a response bias, another explanation must be obtained.

With some consideration, it seems possible that higher ratings for older adults may be caused by the simple fact that older adults have lived longer than younger adults. Thus, as people get older, they will find themselves exposed to objects more often (increased frequency) and obtain more knowledge about the concepts that they are exposed to (increased familiarity, imageability). To explain why children rated items as less familiar than did adults, Cycowicz et al. (1997) argued that children presumably have less experience with some of the objects investigated. Applying this idea to the present results, the fact that older adults have acquired more experience of concepts than have younger adults is reflected by the older adults' smaller percentage of unknown responses. Also, with increasing age, the higher typicality ratings may be the result of better defined category structures being developed, which could be affected by increased frequency of exposure to and/or familiarity with concepts. Such evidence was reported by Johnson (2001), in a study comparing typicality ratings of novices and bird experts. Johnson reported that experts rated exemplars with which they had detailed knowledge as more typical than novices did. When these groups were also asked to rate exemplars of which the bird experts had little knowledge, the typicality ratings produced were similar in both groups (furthermore, the ratings obtained from the experts for these exemplars were significantly less than those obtained for the exemplars with which they were familiar). Johnson reported that the typicality ratings of the experts were primarily determined by subjective familiarity, whereas this was not the case for the novices. These results verify the strong positive correlations between typicality and familiarity for both age groups, discussed earlier, and add support to the idea that older adults may become "experts" of things that they have had considerable exposure to over many years.

This "expert" theory of semantic representations with aging has also been supported by other findings in recent literature. For example, Allen, Lien, et al. (2002) provided evidence of greater expertise in the processing of semantic concepts with age, since the performance of older adults suggested superior parallel processing compared with that of younger adults in a task involving lexical access. Also, Verhaeghen (2003) carried out a meta-analysis of vocabulary scores on studies of healthy younger and older samples. Verhaeghen reported that older adults demonstrated consistently and significantly higher vocabulary test scores than did younger adults, to the extent that the author suggested "it would be difficult to find samples for which the young outperform the old on vocabulary scores" (p. 339). Although this result was interpreted with regard to possible cohort effects or sample selection biases, another interpretation is that it is further evidence for the expert theory of semantic processing with aging - in particular, that older adults have acquired greater semantic knowledge (more stable word representations and/or a greater number of word representations) throughout their longer lives relative to younger adults. The implications of the expert theory for studies of healthy aging will be addressed later in this article.

Regarding the higher ratings for age of acquisition, the age at which concepts were first encountered and object knowledge acquired would be expected to be later for older adults than for younger adults, reflecting technological advances (e.g., for vehicles and tools), the availability of foreign imports (e.g., fruits and vegetables), increased travel opportunities, and the vast increase in the knowledge that is available via media such as television documentaries (e.g., allowing people to obtain knowledge of nonnative animals). For example, younger adults would have learned about modern methods of transport from a very early age, whereas older adults would have learned of such vehicles later in life as they were invented and modernized. ${ }^{4}$ Another possibility regarding the interpretation of age differences for age-of-acquisition ratings is that, since older adults will have to recollect back many more years than younger adults to ascertain approximate ages of learning new words, they may not actually remember this as accurately as younger adults. Thus, age of acquisition might be a difficult concept for which to obtain ratings for beneficial comparison between age groups. However, in the absence of any objective measures for the older age group, such subjective ratings must surely be an improvement on the alternative (i.e., assuming similar ages of acquisition for older and younger people), because at least some of the assumed ratings for older adults, as based on the ratings of younger adults, must be incorrect because of, for example, technological advances, as discussed above. Note also that, despite this possible problem with comparing age-of-acquisition ratings between age groups, the ratings for different categories of information within the older age group would not be detrimentally affected by this.

\section{Visual Complexity and Aging}

The age difference in the ratings obtained for visual complexity appears at first glance more difficult to explain. The objective complexity of an object should not change, irrespective of the age of the perceiver. However, since the participants were asked to rate the visual complexity of a typical object, without any such object or pictorial representation of it actually being present, the ratings of visual complexity should reflect the complex- 
Table 6

Correlation and $t$-Test Comparisons Between Younger and Older Adults' Ratings on Items From 14 Categories

\begin{tabular}{|c|c|c|c|c|c|c|c|c|c|}
\hline \multirow[b]{2}{*}{ Category } & \multirow[b]{2}{*}{$n$} & \multicolumn{4}{|c|}{ Typicality } & \multicolumn{4}{|c|}{ Familiarity } \\
\hline & & Younger & Older & $r$ & $t$ & Younger & Older & $r$ & $t$ \\
\hline Animals & 135 & 4.624 & 4.958 & $.929^{* * *}$ & $11.048^{* * *}$ & 4.589 & 4.248 & $.853^{* * *}$ & $-7.537^{* * *}$ \\
\hline Birds & 79 & 5.026 & 5.388 & $.866^{* * *}$ & $8.660^{* * *}$ & 4.558 & 4.590 & $.838^{* * *}$ & 0.529 \\
\hline Flowers & 55 & 5.025 & 5.828 & $.701^{* * *}$ & $10.293^{* * *}$ & 4.409 & 5.678 & $.660^{* * *}$ & $12.468^{* * *}$ \\
\hline Fruit & 68 & 4.510 & 5.185 & $.873^{* * *}$ & $9.215^{* * *}$ & 4.923 & 5.147 & $.851^{* * *}$ & $2.923^{* *}$ \\
\hline Insects & 56 & 4.939 & 4.983 & $.878^{* * *}$ & 0.753 & 4.650 & 4.251 & $.886^{* * *}$ & $-5.343^{* * *}$ \\
\hline Trees & 11 & 5.286 & 5.802 & - & - & 4.744 & 5.134 & - & - \\
\hline Vegetables & 40 & 4.946 & 5.534 & $.892^{* * *}$ & $7.638^{* * *}$ & 5.235 & 5.421 & $.821^{* * *}$ & 1.98 \\
\hline Clothing & 110 & 4.748 & 5.467 & $.834^{* * *}$ & $11.884^{* * *}$ & 5.422 & 5.700 & $.740^{* * *}$ & $4.749^{* * *}$ \\
\hline Cutlery & 3 & 6.918 & 6.842 & - & - & 6.843 & 6.842 & - & - \\
\hline Furniture & 66 & 4.759 & 5.609 & $.762^{* * *}$ & $8.140^{* * *}$ & 5.824 & 6.103 & $.750^{* * *}$ & $4.366^{* * *}$ \\
\hline Instruments & 75 & 4.491 & 4.810 & $.881^{* * *}$ & $5.513^{* * *}$ & 4.445 & 4.120 & $.745^{* * *}$ & $-3.916^{* * *}$ \\
\hline Jewelry & 20 & 5.032 & 5.094 & $.904^{* * *}$ & 0.480 & 5.374 & 4.972 & $.752^{* * *}$ & -1.73 \\
\hline Tools & 82 & 4.782 & 5.399 & $.792^{* * *}$ & $11.187^{* * *}$ & 4.921 & 5.350 & $.837^{* * *}$ & $7.644^{* * *}$ \\
\hline Vehicles & 88 & 4.030 & 4.861 & $.895^{* * *}$ & $14.516^{* * *}$ & 4.912 & 4.927 & $.805^{* * *}$ & 0.248 \\
\hline
\end{tabular}

ity of the image as it is subjectively perceived and, hence, represented in the brain. As with familiarity, perhaps as exposure to an object increases over the years, knowledge of the visual characteristics should increase. This would mean that older adults would be more familiar with the salient visual characteristics and be more able to conjure up an image of an object in their heads (as reflected in the increased imageability ratings); therefore, it makes sense that they would also gain more knowledge of the finer grained visual characteristics and so deem objects as more visually complex. This argument predicts a close correlation between visual complexity and familiarity and/or frequency. However, there are two limitations to this. First, the frequency measure, as defined in this study, includes all exposure to a concept, including the written word, and thus exposure to and awareness of the visual features would not be increased with every encounter of a concept's name. Second, no matter how well known an object is to any perceiver, there must be a ceiling on the visual complexity ratings of some simple objects (perhaps, e.g., a pea or an orange). This means then that the relationship between visual complexity and frequency cannot be straightforward and so perhaps explains the absence of a strong, positive correlation between these measures.

To test whether the age differences in visual complexity ratings reflect, at least to some extent, the frequency of exposure to an object and/or familiarity, further tests were carried out. From a total of 888 objects, 714 objects obtained higher ratings of visual complexity from older adults than from younger adults; for these items, the familiarity and frequency ratings were also higher for older adults. For the 174 items rated more highly on visual complexity by younger adults, the familiarity and frequency ratings were similarly higher for younger adults. ${ }^{5}$ These results demonstrate strong support for the hypothesis that the visual complexity of an object as represented in the brain is modulated at least partially by the frequency of exposure to the object and/or familiarity with it.

The patterns of correlation involving visual complexity are rather complex and seem to be modulated by age to some degree. In particular, visual complexity ratings correlated negatively with familiarity, frequency, and imageability (and also typicality for manmade items only) for younger adults, whereas the correlations were mostly nonsignificant for older adults. Whether this effect was due to differences in the way these items were processed and represented with aging or were affected by the participants' ability to recall visual characteristics of objects, for example, is unclear. Although further investigation of this issue is required to elucidate on the cause of these differences, such investigation is beyond the scope of this paper; however, it should be noted that these differences exist and should be taken into account in studies involving concrete, imageable words.

\section{Implications and Summary}

Finally, some consideration ought to be given to the possible implications of these normative ratings of stimuli attributes to lexical-semantic processing. One important implication is related to the issue of whether the representation of semantic concepts in the brain is the same for younger and older adults, as measured by these normative ratings. The high correlations of the ratings from younger and older adults provide no evidence of qualitative age differences in the representations. However, the results of the $t$ tests comparing ratings between age groups suggest that there are quantitative differences. Overall, the results of this study provide no evidence of any deficit in the representations of semantic concepts as a function of age: On the contrary, there is evidence that in fact older adults may have better representations, suggesting a greater level of expertise. This is due to the finding of higher ratings on most measures for older adults than for younger adults.

It could be argued that if items are more frequent or familiar to older adults, then their representations may be more accessible, or salient, in semantic memory than those for younger adults. The effect of higher levels of saliency for semantic concepts may normally be manifested within any particular cohort as faster or more accurate processing. Certainly, in semantic tasks, such as 
Table 6 (Continued)

Correlation and $t$-Test Comparisons Between Younger and Older Adults' Ratings on Items From 14 Categories

\begin{tabular}{|c|c|c|c|c|c|c|c|c|c|c|c|}
\hline \multicolumn{4}{|c|}{ Frequency } & \multicolumn{4}{|c|}{ Visual Complexity } & \multicolumn{4}{|c|}{ Imageability } \\
\hline Younger & Older & $r$ & $t$ & Younger & Older & $r$ & $t$ & Younger & Older & $r$ & $t$ \\
\hline 3.258 & 2.955 & $.896^{* * *}$ & $-8.260^{* * *}$ & 3.990 & 4.042 & $.735^{* * *}$ & $2.074^{*}$ & 5.262 & 5.572 & $.874^{* * *}$ & $9.220^{* * *}$ \\
\hline 3.343 & 3.430 & $.852^{* * *}$ & 1.338 & 3.999 & 4.178 & $.692^{* * *}$ & $5.932^{* * *}$ & 4.956 & 5.473 & $.813^{* * *}$ & $9.612^{* * *}$ \\
\hline 3.386 & 4.756 & $.649^{* * *}$ & $13.944^{* * *}$ & 3.715 & 4.237 & $.573^{* * *}$ & $13.254^{* * *}$ & 4.915 & 6.040 & $.689^{* * *}$ & $12.569^{* * * *}$ \\
\hline 3.966 & 4.216 & $.898^{* * *}$ & $3.583^{* * *}$ & 2.566 & 2.918 & $.605^{* * *}$ & $7.979^{* * *}$ & 5.474 & 5.828 & $.843^{* * *}$ & $5.816^{\text {*** }}$ \\
\hline 3.450 & 3.193 & $.905^{* * *}$ & $-3.723^{* * *}$ & 3.809 & 3.920 & $.643^{* * *}$ & 1.703 & 5.024 & 5.137 & $.896^{* * *}$ & 1.976 \\
\hline 3.802 & 4.307 & - & - & 3.884 & 4.050 & - & - & 5.184 & 5.825 & - & - \\
\hline 4.518 & 4.751 & $.863^{* * *}$ & $2.281^{*}$ & 2.511 & 3.034 & $.767^{* * *}$ & $10.380^{* * *}$ & 5.689 & 6.012 & $.804^{* * *}$ & $4.313^{* * *}$ \\
\hline 4.534 & 4.696 & $.857^{* * *}$ & $2.281^{*}$ & 2.688 & 3.103 & $.742^{* * *}$ & $12.737^{* * *}$ & 6.018 & 6.317 & $.639^{* * *}$ & $7.247^{* * *}$ \\
\hline 6.950 & 6.861 & - & - & 2.031 & 2.918 & - & - & 6.779 & 6.866 & - & - \\
\hline 5.413 & 5.561 & $.836^{* * *}$ & 1.712 & 2.991 & 3.517 & $.818^{* * *}$ & $13.338^{* * *}$ & 6.151 & 6.410 & $.733^{* * *}$ & $5.931^{* * *}$ \\
\hline 3.231 & 2.960 & $.861^{* * *}$ & $-4.570^{* * *}$ & 3.781 & 3.843 & $.812^{* * *}$ & 1.035 & 5.113 & 5.386 & $.720^{* * *}$ & $3.59^{* *}$ \\
\hline 4.574 & 4.072 & $.853^{* * *}$ & $-2.596^{*}$ & 2.992 & 3.417 & $.924^{* * *}$ & $5.109^{* * *}$ & 6.019 & 6.118 & $.449^{*}$ & 0.828 \\
\hline 3.733 & 4.106 & $.876^{* * *}$ & $6.265^{* * *}$ & 2.887 & 3.171 & $.893^{* * *}$ & $9.059^{* * *}$ & 5.483 & 5.987 & $.787^{* * *}$ & $10.327^{* * *}$ \\
\hline 3.811 & 3.747 & $.924^{* * *}$ & -1.266 & 3.898 & 4.243 & $.880^{* * * *}$ & $10.092^{* * *}$ & 5.668 & 6.073 & $.735^{* * *}$ & $9.081^{* * *}$ \\
\hline
\end{tabular}

lexical decision and category verification, there have been reports of greater accuracy for older adults than for younger adults (e.g., Allen, Lien, et al., 2002; Morrow, 2001). However, such age differences affected by saliency will be more difficult to identify in the comparison of response times. This is because response times, and presumably processing speed in general, are slowed with healthy aging; hence, no matter how salient any items are to older adults, the items are unlikely to elicit faster responses in any task, relative to younger adults. Perhaps reports of larger priming effects in older adults, even when response times between age groups have been accounted for (e.g., Laver, 2000), may be caused by the increased salience of items in the semantic memories of older adults. In a study designed to separate the processing of semantic information from other processes, Allen, Sliwinski, and Bowie (2002) provided evidence that older adults can perform central processes for semantic tasks (e.g., lexical access) similarly to younger adults, in contrast to evidence of agerelated slowing in central processes for episodic tasks and peripheral processes (e.g., encoding, response execution) for both episodic and semantic tasks. Therefore, it would seem that, although some processes are affected by aging, the level of expertise that older adults have acquired allows them to perform central semantic processes as efficiently as younger adults and without the same degree of slowing that affects other processes. Perhaps one of the reasons that peripheral processes are deleteriously affected by healthy aging is that these involve reliance on sensory processes. Since less light reaches the retina of older adults than that of younger adults, this is likely to have a profound effect on older adults' sensory abilities. ${ }^{6}$ This theory of slower peripheral processes with aging would certainly account for the overall slower performance of older adults on semantic tasks, despite having developed superior semantic knowledge relative to younger adults.

This means that when stimuli are selected for a study of healthy aging, these stimuli are, in general, likely to be more salient for older adults than for younger adults. Perhaps controlling the saliency of stimuli between age groups would actually exacerbate the age differences, since older adults would no longer have the semantic advantage. Previous studies of age differences may therefore have underestimated the actual age differences that exist.

The evidence of age differences in the representation of semantic concepts suggests that normative data collected from younger adults do not accurately reflect the saliency of semantic concepts in the semantic store of older adults. If the qualitative aspect of age effects on the semantic store is being investigated in a particular study, then it may not be necessary to use different normative data for each age group in order to control stimuli. However, if quantitative aspects are being investigated, then these age-appropriate norms should be used, with the age differences in ratings accounted for in the analysis or interpretation of the data. In studies of category-specific deficits with neuropsychological patients, it seems that equating natural and manmade stimuli on age-appropriate normative data would help to exclude yet more confounds associated with stimuli selection. Thus, use of these norms depends on the particular aims of an experiment.

Finally, it should be noted that, in addition to the concept attributes for which norms were collected in the present study, there may be other variables that are relevant to the processing of the concepts of natural and manmade, at least with some tasks. Sartori and Lombardi (2004) suggested that the relevance of semantic features to semantic concepts (such as "has webbed feet" for gull) may also have an effect on the representation and processing of such concepts. Furthermore, they provided evidence of category differences, whereby natural concepts had more features and had lower relevance than those related to manmade concepts. Thus, this suggestion should be considered in tasks using semantic features to investigate access to semantic concepts.

In summary, this study has demonstrated that differences exist in the salience of concept attributes for natural and manmade item category exemplars, both between ontological groupings and cohorts of younger and older adults. Perhaps the most lucid explanation of the over- 
Table 6 (Continued)

Correlation and $t$-Test Comparisons Between Younger and Older Adults' Ratings on Items From 14 Categories

\begin{tabular}{|c|c|c|c|c|c|c|c|c|}
\hline \multirow[b]{2}{*}{ Category } & \multicolumn{4}{|c|}{ Age of Acquisition } & \multicolumn{4}{|c|}{ Unknown (\%) } \\
\hline & Younger & Older & $r$ & $t$ & Younger & Older & $r$ & $t$ \\
\hline Animals & 3.924 & 5.313 & $.875^{* * *}$ & $27.960^{* * *}$ & 6.035 & 4.835 & $.602^{* * *}$ & -1.245 \\
\hline Birds & 4.211 & 5.433 & $.834^{* * *}$ & $19.210^{* * *}$ & 10.639 & 3.957 & $.767^{* * *}$ & $-4.610^{* * *}$ \\
\hline Flowers & 4.527 & 5.036 & $.821^{* * *}$ & $6.465^{* * *}$ & 19.063 & 2.232 & $.631^{* * *}$ & $-6.399^{* * *}$ \\
\hline Fruit & 4.145 & 5.193 & $.849^{* * *}$ & $12.154^{* * *}$ & 8.602 & 4.840 & $.766^{* * *}$ & $-2.329^{*}$ \\
\hline Insects & 4.083 & 5.397 & $.878^{* * *}$ & $17.065^{* * *}$ & 12.225 & 9.082 & $.707^{* * *}$ & -1.636 \\
\hline Trees & 4.293 & 5.392 & - & - & 4.803 & 1.696 & - & - \\
\hline Vegetables & 4.088 & 5.248 & $.792^{* * *}$ & $9.097^{* * *}$ & 4.692 & 1.782 & $.937^{* * *}$ & -1.839 \\
\hline Clothing & 3.483 & 4.867 & $.570^{* * *}$ & $11.517^{* * *}$ & 2.376 & .860 & $.483^{* * *}$ & $-2.523^{*}$ \\
\hline Cutlery & 1.774 & 2.337 & - & - & 0 & 0 & - & - \\
\hline Furniture & 3.246 & 4.388 & $.673^{* * *}$ & $8.586^{* * *}$ & 3.173 & .915 & .180 & -1.816 \\
\hline Instruments & 4.755 & 5.960 & $.708^{* * *}$ & $12.861^{* * *}$ & 20.739 & 10.479 & $.667^{* * *}$ & $-4.251^{* * *}$ \\
\hline Jewelry & 4.352 & 5.343 & $.889^{* * *}$ & $6.481^{* * *}$ & .472 & 1.955 & -.198 & 1.483 \\
\hline Tools & 4.530 & 5.414 & $.868^{* * *}$ & $14.725^{* * *}$ & 10.392 & 3.592 & $.654^{* * *}$ & $-4.772^{* * *}$ \\
\hline Vehicles & 3.796 & 5.364 & $.670^{* * *}$ & $15.232^{* * *}$ & 5.102 & 1.466 & $.553^{* * *}$ & $-2.671^{* *}$ \\
\hline
\end{tabular}

Table 7

Comparisons of $t$ Tests Between the Ratings for Natural and Manmade Items Within Age Groups

\begin{tabular}{|c|c|c|c|c|c|c|c|}
\hline Age Group & Typicality & Familiarity & Frequency & Visual Complexity & Imageability & $\begin{array}{c}\text { Age of } \\
\text { Acquisition }\end{array}$ & Unknown \\
\hline Younger & $-3.00^{* *}$ & $6.861^{* * *}$ & $7.413^{* * *}$ & $-7.225^{* * *}$ & $9.403^{* * *}$ & $-2.364^{*}$ & -1.688 \\
\hline Older & -0.269 & $6.618^{* * *}$ & $5.852^{* * *}$ & $-5.955^{* * *}$ & $9.046^{* * *}$ & -1.211 & $-2.445^{*}$ \\
\hline
\end{tabular}

Note-The means for these comparisons are presented in Table $5 .{ }^{*} p<.05 .{ }^{* *} p<.01 .{ }^{* * *} p<.001$.

all higher ratings from older adults relative to younger adults on all measures is that older adults have superior knowledge of and experience with natural and manmade items in the environment, in line with the "expert" theory. Although this expert hypothesis fits well with the higher ratings of visual complexity for older adults, clearly more work is required to explain the apparent independence of visual complexity ratings to those of the other measures for older adults. The strong correlations of ratings between cohorts suggest a quantitative, rather than qualitative, difference between groups in how concepts are represented in semantic memory. The age differences featured in this study also demonstrate the fundamental importance of using stimuli that are properly controlled on concept attributes for younger and older adults on age-appropriate ratings, and the normative data featured in this article provide a means of doing so.

\section{REFERENCES}

Allen, P. A., Goldstein, B., Madden, D. J., \& Mitchell, D. B. (1997). Adult age differences in long-term semantic priming. Experimental Aging Research, 23, 107-135.

Allen, P. A., Lien, M. C., Murphy, M. D., Sanders, R. E., Judge, K. S., \& McCanN, R. S. (2002). Age differences in overlappingtask performance: Evidence for efficient parallel processing in older adults. Psychology \& Aging, 17, 505-519.

Allen, P. A., Sliwinski, M., \& Bowie, T. (2002). Differential age effects in semantic and episodic memory: Part II. Slope and intercept analyses. Experimental Aging Research, 28, 111-142.

Balota, D. A., Pilotti, M., \& Cortese, M. J. (2001). Subjective frequency estimates for 2,938 monosyllabic words. Memory \& Cognition, 29, 639-647.
Battig, W. F., \& Montague, W. E. (1969). Category norms for verbal items in 56 categories: A replication and extension of the Connecticut category norms. Journal of Experimental Psychology, 80(3, Pt. 2), $1-46$.

Berman, S., Friedman, D., Hamberger, M., \& Snodgrass, J. G. (1989). Developmental picture norms: Relationships between name agreement, familiarity, and visual complexity for child and adult ratings of two sets of line drawings. Behavior Research Methods, Instruments, \& Computers, 21, 371-382.

BJorklund, D. F., Thompson, B. E., \& Ornstein, P. A. (1983). Developmental trends in children's typicality judgments. Behavior Research Methods \& Instrumentation, 15, 350-356.

Bowles, N. L., Williams, D., \& Poon, L. W. (1983). On the use of word-association norms in aging research. Experimental Aging Research, 9, 175-177.

Brosseau, J., \& Cohen, H. (1996). The representation of semantic categories in aging. Experimental Aging Research, 22, 381-391.

Brown, A. S., \& Mitchell, D. B. (1991). Age differences in retrieval consistency and response dominance. Journals of Gerontology, 46, P332-P339.

Conley, P., \& Burgess, C. (2000a). Age effects in a computational model of memory. Brain \& Cognition, 43, 104-108.

Conley, P., \& Burgess, C. (2000b). A computational approach to modeling population differences. Behavior Research Methods, Instruments, \& Computers, 32, 274-279.

Cycowicz, Y. M., Friedman, D., Rothstein, M., \& Snodgrass, J. G. (1997). Picture naming by young children: Norms for name agreement, familiarity, and visual complexity. Journal of Experimental Child Psychology, 65, 171-237.

FisheR, R. A. (1921). On the probable error of a coefficient of correlation deduced from a small sample. Metron, 1, 3-32.

Francis, W. N., \& Kučera, H. (1982). Frequency analysis of English usage: Lexicon and grammar. Boston: Houghton Mifflin.

Friederici, A. D., Schriefers, H., \& Lindenberger, U. (1998). Differential age effects on semantic and syntactic priming. International Journal of Behavioral Development, 22, 813-845.

Hines, D., Czerwinski, M., Sawyer, P. K., \& Dwyer, M. (1986). 
Automatic semantic priming: Effect of category exemplar level and word-association level. Journal of Experimental Psychology: Human Perception \& Performance, 12, 370-379.

Hirsh, K. W., \& Tree, J. J. (2001). Word association norms for two cohorts of British adults. Journal of Neurolinguistics, 14, 1-44.

HowaRD, D. V. (1979). Restricted word association norms for adults between the ages of 20 and 80. JSAS: Catalog of Selected Documents in Psychology, 10(6) (MS. No. 1991).

HowarD, D. V. (1980). Category norms: A comparison of the Battig and Montague (1969) norms with the responses of adults between the ages of 20 and 80. Journal of Gerontology, 35, 225-231.

HumPHREYS, G. W., \& RiDDOCH, M. J. (1987). On telling your fruit from your vegetables: A consideration of category-specific deficits after brain damage. Trends in Neurosciences, 10, 145-148.

Johnson, K. E. (2001). Impact of varying levels of expertise on decisions of category typicality. Memory \& Cognition, 29, 1036-1050.

Kellenbach, M. L., Wijers, A. A., \& Mulder, G. (2000). Visual semantic features are activated during the processing of concrete words: Event-related potential evidence for perceptual semantic priming. Cognitive Brain Research, 10, 67-75.

LAVER, G. D. (2000). A speed-accuracy analysis of word recognition in young and older adults. Psychology \& Aging, 15, 705-709.

Light, L. L. (2000). Memory changes in adulthood. In S. H. Qualls \& N. Abeles (Eds.), Psychology and the aging revolution: How we adapt to longer life (pp. 73-97). Washington, DC: American Psychological Association.

Morrison, C. M., Chappell, T. D., \& Ellis, A. W. (1997). Age of acquisition norms for a large set of object names and their relation to adult estimates and other variables. Quarterly Journal of Experimental Psychology, 50A, 528-559.

Morrison, C. M., Hirsh, K. W., Chappell, T. D., \& Ellis, A. W. (2002). Age and age of acquisition: An evaluation of the cumulative frequency hypothesis. European Journal of Cognitive Psychology, $14,435-459$.

Morrow, L. I. (2001). Ontological category specific effects in word processing: The influences of age, strategy use and stimuli attributes. Unpublished thesis, University of Glasgow, Scotland.

Moss, H. E., Tyler, L. K., \& Jennings, F. (1997). When leopards lose their spots: Knowledge of visual properties in category-specific deficits for living things. Cognitive Neuropsychology, 14, 901-950.

Myerson, J., Hale, S., Chen, J., \& Lawrence, B. (1997). General lexical slowing and the semantic priming effect: The roles of age and ability. Acta Psychologica, 96, 83-101.

Nelson, H. E. (1982). The National Adult Reading Test (NART): Test manual. Windsor: NFER.

Parkin, A. J., \& Stewart, F. (1993). Category-specific impairments? No. A critique of Sartori et al. Quarterly Journal of Experimental Psychology, 46A, 505-509.

Perlmutter, M., \& Mitchell, D. B. (1982). The appearance and disappearance of age differences in adult memory. In F. I. M. Craik \& S. Trehub (Eds.), Aging and cognitive processes (pp. 127-144). New York: Plenum.

Pompéia, S., Miranda, M. C., \& Bueno, O. F. A. (2001). A set of 400 pictures standardised for Portuguese: Norms for name agreement, familiarity and visual complexity for children and adults. Arquivos de Neuro-Psiquiatria, 59, 330-337.

Rochford, G., \& WiLliams, M. (1962). Studies in the development and breakdown of the use of names. Journal of Neurology, Neurosurgery, \& Psychiatry, 25, 222-233.

SAFFran, E. M., \& ShOll, A. (1999). Clues to the functional and neural architecture of word meaning. In C. M. Brown \& P. Hagoort (Eds.), The neurocognition of language (pp. 241-272). Oxford: Oxford University Press.

SARTORI, G., \& Lombardi, L. (2004). Semantic relevance and semantic disorders. Journal of Cognitive Neuroscience, 16, 439-452.

Scialfa, C. T., \& Margolis, R. B. (1986). Age differences in the commonality of free associations. Experimental Aging Research, 12, 9598.

VERHAEGHEN, P. (2003). Aging and vocabulary scores: A meta-analysis. Psychology \& Aging, 18, 332-339.

WARRINGTON, E. K., \& MCCARTHY, R. [A.] (1983). Category specific access dysphasia. Brain, 106, 859-878.

WARrington, E. K., \& MCCARThy, R. A. (1987). Categories of knowledge-Further fractionations and an attempted integration. Brain, 110, 1273-1296.

WarRington, E. K., \& Shallice, T. (1984). Category specific semantic impairments. Brain, 107, 829-854.

\section{NOTES}

1. Similar arguments regarding objective word frequency measures were made by Balota, Pilotti, and Cortese (2001), although they related their case to the entire exposure to words (e.g., to words spoken, heard, etc., rather than limiting frequency to written words), as opposed to concepts, as in the present study. However, particularly in relation to the exploration of ontological category exemplar processing, it seems that ratings of concept rather than word attributes would be more useful. This is especially the case since, in many studies, researchers have attempted to access category processing using, for example, pictorial stimuli, or probe questions relating to visual or semantic characteristics of the category exemplars, thus accessing attributes of the object itself, not just attributes of the word.

2. The consequence of handling "unknown" responses in this way was that the familiarity rating reflected only how familiar items were to the participants who had some knowledge of the items, and not the ratings of "unknown" for the participants who had no knowledge of the item (similar to Cycowicz, Friedman, Rothstein, \& Snodgrass, 1997). This technique was viewed as preferable, however, for dealing with "unknown" responses consistently across all of the six measurements obtained, rather than dealing differentially with familiarity. In equating stimuli lists from these normative word measurements, the number of "unknown" responses should also be equated as a separate variable.

3. Although the correlations between familiarity and frequency were very high for both age groups and categories, $t$ tests carried out between these measures revealed that the ratings also differed significantly ( $p<$ .0001 ; the lowest $t$ value emerged for younger adults' ratings of manmade items, $t=34.506$ ). Therefore, despite the high correlations, the large differences between ratings suggest that the participants were well able to distinguish between the measures and to rate items accordingly.

4. In support of this idea, the greatest difference between the age-ofacquisition ratings for younger and older adults was obtained for the category of vehicles, for which the mean for younger adults was 3.796 on the ratings scale, corresponding to 5-6 years of age, and the mean for older adults was 5.364, corresponding to 9-10 years of age.

5. For familiarity and frequency, the $t$ values were 3.8 and 3.7 ( $p<$ .01 ) for the items rated more highly on visual complexity by younger adults, and 6.6 and $5.8(p<.01)$ for those given higher visual complexity ratings by the older adults.

6. The authors are grateful to Philip A. Allen for suggesting this possibility 
APPENDIX A

Normative Ratings of Exemplars From the Animal Category From Younger Adults

\begin{tabular}{|c|c|c|c|c|c|c|c|c|c|c|c|c|c|c|}
\hline \multirow[b]{3}{*}{ Subcategory } & \multirow[b]{3}{*}{ Exemplar } & \multirow{2}{*}{\multicolumn{2}{|c|}{ Typicality }} & \multicolumn{3}{|c|}{ Familiarity } & \multirow{2}{*}{\multicolumn{4}{|c|}{$\begin{array}{c}\text { Visual } \\
\text { Complexity }\end{array}$}} & \multirow{2}{*}{\multicolumn{2}{|c|}{ Imageability }} & \multirow{2}{*}{\multicolumn{2}{|c|}{$\begin{array}{c}\text { Age of } \\
\text { Acquisition }\end{array}$}} \\
\hline & & & & & & Unknown & & & & & & & & \\
\hline & & $M$ & $S D$ & $M$ & $S D$ & $(\%)$ & $M$ & $S D$ & $M$ & $S D$ & $M$ & $S D$ & $M$ & $S D$ \\
\hline \multirow[t]{60}{*}{ Animals } & aardvark & 4.122 & 1.703 & 3.980 & 1.601 & 7.547 & 2.816 & 1.590 & 4.071 & 1.257 & 4.262 & 1.449 & 4.878 & 1.269 \\
\hline & alligator & 4.811 & 1.494 & 4.830 & 1.424 & 0 & 3.226 & 1.463 & 4.442 & 1.392 & 5.698 & 1.119 & 3.472 & 0.992 \\
\hline & anteater & 3.846 & 1.797 & 3.981 & 1.686 & 1.887 & 2.731 & 1.483 & 4.204 & 1.399 & 4.612 & 1.766 & 4.392 & 1.250 \\
\hline & antelope & 4.566 & 1.658 & 4.173 & 1.339 & 0 & 2.755 & 1.239 & 4.059 & 1.333 & 4.647 & 1.683 & 4.434 & 1.135 \\
\hline & ape & 5.736 & 1.163 & 5.245 & 1.285 & 0 & 3.868 & 1.653 & 4.396 & 1.472 & 5.885 & 1.182 & 3.294 & 0.986 \\
\hline & armadillo & 4.040 & 1.873 & 4.000 & 1.666 & 5.660 & 2.620 & 1.260 & 4.625 & 1.299 & 4.917 & 1.609 & 4.920 & 1.243 \\
\hline & ass & 4.491 & 1.683 & 4.377 & 1.522 & 0 & 3.019 & 1.538 & 3.615 & 1.286 & 5.096 & 1.418 & 4.094 & 1.244 \\
\hline & baboon & 4.679 & 1.615 & 4.434 & 1.487 & 0 & 2.925 & 1.398 & 4.538 & 1.501 & 5.000 & 1.532 & 4.245 & 1.191 \\
\hline & badger & 5.245 & 1.543 & 4.792 & 1.536 & 0 & 3.358 & 1.482 & 4.245 & 1.426 & 5.887 & 0.993 & 3.340 & 0.939 \\
\hline & bat & 4.340 & 1.698 & 5.170 & 1.383 & 0 & 3.547 & 1.624 & 3.887 & 1.476 & 5.585 & 1.322 & 3.327 & 0.810 \\
\hline & bear & 6.208 & 1.007 & 5.642 & 1.331 & 0 & 4.075 & 1.651 & 3.788 & 1.333 & 6.189 & 1.039 & 2.358 & 1.021 \\
\hline & beaver & 4.698 & 1.612 & 4.736 & 1.643 & 0 & 3.208 & 1.485 & 3.887 & 1.476 & 5.269 & 1.443 & 3.731 & 1.031 \\
\hline & $\begin{array}{l}\text { bison } \\
\text { black }\end{array}$ & 4.449 & 1.768 & 3.816 & 1.409 & 7.547 & 2.208 & 0.898 & 4.128 & 1.279 & 4.915 & 1.442 & 5.167 & 1.277 \\
\hline & widow & 4.431 & 2.081 & 4.275 & 1.698 & 3.774 & 2.706 & 1.418 & 4.449 & 1.355 & 4.959 & 1.513 & 4.900 & 1.266 \\
\hline & buffalo & 4.679 & 1.566 & 4.151 & 1.420 & 0 & 2.830 & 1.312 & 4.038 & 1.372 & 5.075 & 1.371 & 4.094 & 1.024 \\
\hline & camel & 5.038 & 1.519 & 5.189 & 1.415 & 0 & 3.472 & 1.552 & 4.038 & 1.240 & 6.075 & 1.053 & 3.208 & 1.026 \\
\hline & cat & 6.887 & 0.375 & 6.660 & 0.732 & 0 & 6.491 & 0.869 & 3.792 & 1.758 & 6.755 & 0.617 & 1.736 & 0.812 \\
\hline & cheetah & 5.283 & 1.459 & 4.717 & 1.561 & 0 & 3.057 & 1.512 & 4.264 & 1.416 & 5.679 & 1.312 & 3.846 & 1.036 \\
\hline & chimpanzee & 5.736 & 1.375 & 5.283 & 1.486 & 0 & 3.792 & 1.598 & 4.208 & 1.536 & 5.577 & 1.446 & 3.132 & 1.075 \\
\hline & chinchilla & 4.048 & 2.012 & 3.634 & 1.771 & 21.154 & 2.381 & 1.147 & 4.111 & 1.282 & 4.361 & 1.606 & 5.381 & 1.361 \\
\hline & chipmunk & 4.000 & 1.743 & 3.849 & 1.574 & 0 & 2.660 & 1.344 & 4.280 & 1.179 & 4.480 & 1.432 & 4.250 & 1.100 \\
\hline & $\operatorname{cod}$ & 3.038 & 1.860 & 5.113 & 1.489 & 0 & 4.226 & 1.515 & 2.885 & 1.132 & 4.846 & 1.513 & 3.830 & 0.995 \\
\hline & cougar & 4.061 & 1.983 & 2.970 & 1.610 & 36.538 & 2.303 & 1.287 & 4.276 & 1.192 & 3.793 & 1.677 & 5.242 & 1.275 \\
\hline & cow & 6.692 & 0.544 & 6.327 & 0.964 & 0 & 5.731 & 1.239 & 3.731 & 1.586 & 6.538 & 0.753 & 1.904 & 0.823 \\
\hline & coyote & 4.020 & 1.790 & 3.660 & 1.533 & 5.660 & 2.600 & 1.485 & 4.000 & 1.258 & 4.409 & 1.604 & 4.429 & 1.323 \\
\hline & $\mathrm{crab}$ & 4.019 & 1.670 & 5.113 & 1.368 & 0 & 3.472 & 1.367 & 4.208 & 1.364 & 5.792 & 1.261 & 3.038 & 1.018 \\
\hline & crocodile & 4.962 & 1.544 & 5.113 & 1.219 & 0 & 3.170 & 1.451 & 4.491 & 1.382 & 6.019 & 1.065 & 3.019 & 0.930 \\
\hline & deer & 5.615 & 1.207 & 5.519 & 1.213 & 0 & 3.846 & 1.526 & 4.192 & 1.373 & 6.000 & 1.155 & 3.132 & 1.001 \\
\hline & dingo & 3.778 & 1.964 & 3.444 & 1.358 & 15.094 & 2.267 & 1.304 & 3.512 & 1.247 & 4.225 & 1.510 & 5.133 & 1.100 \\
\hline & $\operatorname{dog}$ & 6.925 & 0.331 & 6.698 & 0.638 & 0 & 6.509 & 0.800 & 3.887 & 1.660 & 6.774 & 0.609 & 1.604 & 0.793 \\
\hline & dolphin & 4.755 & 1.651 & 5.509 & 1.234 & 0 & 4.038 & 1.556 & 3.698 & 1.339 & 6.283 & 1.026 & 3.283 & 1.133 \\
\hline & $\begin{array}{l}\text { donkey } \\
\text { duck-billed }\end{array}$ & 5.698 & 1.153 & 5.264 & 1.332 & 0 & 3.830 & 1.528 & 3.755 & 1.299 & 6.115 & 1.041 & 2.635 & 1.030 \\
\hline & platypus & 3.723 & 1.964 & 3.936 & 1.634 & 9.615 & 2.319 & 1.144 & 4.435 & 1.276 & 4.652 & 1.538 & 4.787 & 1.284 \\
\hline & eel & 3.173 & 1.917 & 3.962 & 1.427 & 1.887 & 2.731 & 1.330 & 2.308 & 1.039 & 5.000 & 1.442 & 4.235 & 1.242 \\
\hline & elephant & 6.208 & 1.026 & 5.849 & 1.307 & 0 & 4.245 & 1.616 & 4.283 & 1.378 & 6.491 & 0.846 & 2.453 & 1.048 \\
\hline & elk & 3.976 & 1.891 & 3.350 & 1.594 & 23.077 & 2.275 & 1.109 & 4.394 & 1.298 & 4.303 & 1.403 & 5.256 & 1.272 \\
\hline & ferret & 4.377 & 1.757 & 4.283 & 1.459 & 0 & 2.679 & 1.237 & 3.788 & 1.273 & 4.942 & 1.474 & 4.283 & 1.215 \\
\hline & fox & 6.038 & 1.126 & 5.491 & 1.280 & 0 & 4.057 & 1.574 & 3.868 & 1.287 & 6.151 & 1.045 & 2.830 & 0.871 \\
\hline & frog & 5.208 & 1.691 & 5.811 & 1.287 & 0 & 4.269 & 1.483 & 4.226 & 1.368 & 6.283 & 1.063 & 2.377 & 0.837 \\
\hline & gazelle & 4.646 & 1.695 & 4.063 & 1.479 & 9.434 & 2.688 & 1.307 & 4.085 & 1.213 & 4.745 & 1.661 & 5.042 & 1.220 \\
\hline & gerbil & 5.170 & 1.397 & 5.113 & 1.527 & 0 & 3.660 & 1.427 & 3.528 & 1.324 & 5.528 & 1.395 & 3.434 & 1.135 \\
\hline & giraffe & 5.472 & 1.409 & 5.189 & 1.442 & 0 & 3.358 & 1.469 & 4.509 & 1.502 & 6.189 & 1.039 & 2.887 & 0.934 \\
\hline & gnu & 3.517 & 1.785 & 3.103 & 1.589 & 45.283 & 2.138 & 1.026 & 4.389 & 1.290 & 3.824 & 1.590 & 5.552 & 1.325 \\
\hline & goat & 5.906 & 1.061 & 5.415 & 1.379 & 0 & 4.113 & 1.515 & 3.712 & 1.273 & 5.904 & 1.053 & 2.712 & 0.977 \\
\hline & goldfish & 4.472 & 1.918 & 5.774 & 1.382 & 0 & 4.792 & 1.769 & 2.925 & 1.452 & 6.434 & 0.971 & 2.623 & 0.965 \\
\hline & gopher & 3.729 & 1.921 & 3.833 & 1.826 & 9.434 & 2.458 & 1.487 & 3.500 & 1.254 & 4.357 & 1.650 & 4.563 & 1.219 \\
\hline & gorilla & 5.887 & 1.050 & 5.283 & 1.336 & 0 & 3.792 & 1.680 & 4.415 & 1.537 & 5.906 & 1.079 & 3.212 & 1.016 \\
\hline & guinea pig & 5.264 & 1.534 & 5.321 & 1.478 & 0 & 3.925 & 1.385 & 3.472 & 1.353 & 5.679 & 1.578 & 3.358 & 1.094 \\
\hline & haddock & 2.942 & 1.851 & 4.865 & 1.585 & 0 & 3.865 & 1.358 & 3.400 & 1.400 & 4.980 & 1.518 & 4.173 & 0.985 \\
\hline & hamster & 5.415 & 1.336 & 5.547 & 1.367 & 0 & 4.302 & 1.475 & 3.453 & 1.367 & 5.943 & 1.231 & 3.151 & 1.008 \\
\hline & hare & 5.226 & 1.436 & 4.925 & 1.479 & 0 & 3.302 & 1.588 & 3.547 & 1.435 & 5.679 & 1.221 & 3.585 & 1.046 \\
\hline & hedgehog & 5.472 & 1.310 & 5.615 & 1.286 & 0 & 4.231 & 1.516 & 4.346 & 1.399 & 6.212 & 0.893 & 2.692 & 0.961 \\
\hline & $\begin{array}{l}\text { herring } \\
\text { hippo- }\end{array}$ & 3.115 & 1.711 & 4.500 & 1.627 & 1.887 & 3.288 & 1.637 & 3.240 & 1.205 & 4.540 & 1.681 & 4.288 & 1.073 \\
\hline & potamus & 5.528 & 1.436 & 5.245 & 1.518 & 0 & 3.415 & 1.646 & 3.981 & 1.337 & 5.698 & 1.310 & 3.057 & 1.151 \\
\hline & horse & 6.830 & 0.379 & 6.358 & 0.942 & 0 & 5.642 & 1.257 & 4.170 & 1.729 & 6.604 & 0.743 & 1.962 & 0.831 \\
\hline & hyena & 4.415 & 1.692 & 4.264 & 1.546 & 0 & 2.943 & 1.350 & 4.080 & 1.259 & 4.720 & 1.512 & 4.566 & 1.323 \\
\hline & iguana & 4.040 & 1.807 & 4.140 & 1.666 & 5.660 & 2.760 & 1.479 & 4.543 & 1.361 & 4.761 & 1.676 & 5.347 & 1.284 \\
\hline & impala & 4.300 & 2.214 & 3.700 & 1.636 & 81.132 & 2.500 & 1.080 & 4.625 & 0.916 & 4.250 & 1.753 & 6.100 & 1.101 \\
\hline & jackal & 4.167 & 1.779 & 3.667 & 1.478 & 9.434 & 2.250 & 1.042 & 3.756 & 1.111 & 4.378 & 1.466 & 5.021 & 1.211 \\
\hline & jaguar & 4.755 & 1.697 & 4.208 & 1.536 & 0 & 2.849 & 1.562 & 4.451 & 1.222 & 4.980 & 1.407 & 4.549 & 1.286 \\
\hline
\end{tabular}


APPENDIXA (Continued)

\begin{tabular}{|c|c|c|c|c|c|c|c|c|c|c|c|c|c|c|}
\hline \multirow[b]{3}{*}{ Subcategory } & \multirow[b]{3}{*}{ Exemplar } & \multirow{2}{*}{\multicolumn{2}{|c|}{ Typicality }} & \multicolumn{3}{|c|}{ Familiarity } & \multirow{2}{*}{\multicolumn{2}{|c|}{ Frequency }} & \multirow{2}{*}{\multicolumn{2}{|c|}{$\begin{array}{c}\text { Visual } \\
\text { Complexity }\end{array}$}} & \multirow{2}{*}{\multicolumn{2}{|c|}{ Imageability }} & \multirow{2}{*}{\multicolumn{2}{|c|}{$\begin{array}{c}\text { Age of } \\
\text { Acquisition }\end{array}$}} \\
\hline & & & & & & Unknown & & & & & & & & \\
\hline & & $M$ & $S D$ & $M$ & $S D$ & $(\%)$ & $M$ & $S D$ & $M$ & $S D$ & $M$ & $S D$ & $M$ & $S D$ \\
\hline Animals & jellyfish & 3.528 & 1.683 & 4.925 & 1.398 & 0 & 3.415 & 1.447 & 3.321 & 1.438 & 5.491 & 1.423 & 3.264 & 0.944 \\
\hline & kangaroo & 5.321 & 1.684 & 5.340 & 1.427 & 0 & 3.340 & 1.556 & 4.321 & 1.370 & 6.245 & 0.979 & 3.189 & 1.093 \\
\hline & koala & 4.887 & 1.527 & 4.792 & 1.524 & 0 & 3.096 & 1.347 & 4.075 & 1.238 & 5.774 & 1.339 & 3.635 & 1.121 \\
\hline & lemming & 3.660 & 1.868 & 3.723 & 1.651 & 11.321 & 2.574 & 1.514 & 3.500 & 1.084 & 4.079 & 1.776 & 5.255 & 1.242 \\
\hline & lemur & 3.938 & 1.813 & 3.156 & 1.394 & 39.623 & 2.281 & 1.250 & 3.926 & 1.072 & 3.593 & 1.500 & 5.818 & 1.286 \\
\hline & leopard & 5.462 & 1.527 & 4.885 & 1.580 & 0 & 3.250 & 1.558 & 4.654 & 1.454 & 5.846 & 1.289 & 3.615 & 1.013 \\
\hline & lion & 6.481 & 0.804 & 5.865 & 1.284 & 0 & 4.288 & 1.730 & 4.404 & 1.459 & 6.327 & 0.923 & 2.365 & 0.950 \\
\hline & lizard & 4.396 & 1.656 & 4.623 & 1.457 & 0 & 3.377 & 1.484 & 4.327 & 1.324 & 5.642 & 1.145 & 3.528 & 1.170 \\
\hline & llama & 4.078 & 1.874 & 4.235 & 1.478 & 3.774 & 2.588 & 1.252 & 4.060 & 1.268 & 4.760 & 1.506 & 4.863 & 1.149 \\
\hline & lobster & 3.491 & 1.783 & 4.566 & 1.513 & 0 & 3.151 & 1.336 & 4.925 & 1.222 & 5.566 & 1.337 & 4.113 & 1.086 \\
\hline & lynx & 4.298 & 1.743 & 3.553 & 1.427 & 9.615 & 2.468 & 1.283 & 4.326 & 1.190 & 4.372 & 1.543 & 5.087 & 1.208 \\
\hline & meerkat & 3.667 & 1.897 & 3.806 & 1.818 & 32.075 & 2.222 & 0.898 & 4.333 & 1.295 & 4.655 & 1.587 & 5.771 & 1.262 \\
\hline & $\operatorname{mink}$ & 4.220 & 1.799 & 3.531 & 1.672 & 5.769 & 2.560 & 1.312 & 3.979 & 1.329 & 4.063 & 1.590 & 4.760 & 1.222 \\
\hline & mole & 4.792 & 1.610 & 4.642 & 1.606 & 0 & 3.132 & 1.520 & 3.509 & 1.234 & 5.415 & 1.307 & 3.321 & 1.205 \\
\hline & mongoose & 3.762 & 1.845 & 3.286 & 1.367 & 20.755 & 2.190 & 1.131 & 4.000 & 1.188 & 3.771 & 1.516 & 5.146 & 1.333 \\
\hline & monkey & 6.151 & 1.081 & 5.453 & 1.324 & 0 & 4.302 & 1.793 & 4.189 & 1.415 & 6.151 & 1.063 & 2.481 & 0.852 \\
\hline & moose & 4.377 & 1.746 & 4.038 & 1.593 & 0 & 2.538 & 1.320 & 4.288 & 1.273 & 5.000 & 1.386 & 4.415 & 1.184 \\
\hline & mouse & 5.849 & 1.116 & 5.792 & 1.350 & 0 & 4.321 & 1.541 & 3.340 & 1.372 & 6.321 & 0.803 & 2.415 & 1.008 \\
\hline & mule & 4.615 & 1.635 & 4.269 & 1.573 & 0 & 2.904 & 1.209 & 3.769 & 1.409 & 4.865 & 1.456 & 4.346 & 1.170 \\
\hline & muskrat & 3.500 & 1.972 & 2.393 & 1.227 & 46.154 & 1.786 & 1.031 & 3.571 & 1.505 & 3.385 & 1.557 & 6.500 & 0.906 \\
\hline & newt & 3.549 & 1.858 & 3.784 & 1.540 & 3.774 & 2.529 & 1.189 & 3.833 & 1.310 & 4.396 & 1.425 & 4.275 & 1.133 \\
\hline & ocelot & 3.688 & 2.089 & 2.625 & 1.586 & 69.811 & 1.813 & 0.981 & 4.667 & 0.707 & 4.111 & 1.537 & 5.875 & 1.147 \\
\hline & octopus & 4.038 & 1.754 & 4.868 & 1.401 & 0 & 3.000 & 1.301 & 4.712 & 1.433 & 5.830 & 1.477 & 3.302 & 1.186 \\
\hline & orangutan & 4.811 & 1.665 & 4.547 & 1.435 & 0 & 3.264 & 1.546 & 4.698 & 1.514 & 5.453 & 1.309 & 4.170 & 1.069 \\
\hline & otter & 4.774 & 1.527 & 4.755 & 1.492 & 0 & 3.000 & 1.345 & 3.906 & 1.362 & 5.566 & 1.352 & 3.642 & 0.942 \\
\hline & ox & 4.679 & 1.504 & 4.264 & 1.470 & 0 & 2.849 & 1.460 & 3.846 & 1.406 & 4.846 & 1.589 & 4.170 & 1.221 \\
\hline & panda & 5.434 & 1.435 & 5.377 & 1.376 & 0 & 3.604 & 1.645 & 4.038 & 1.357 & 6.057 & 1.117 & 2.981 & 1.009 \\
\hline & panther & 4.904 & 1.624 & 4.385 & 1.444 & 1.887 & 2.962 & 1.468 & 3.865 & 1.469 & 5.327 & 1.465 & 4.078 & 1.017 \\
\hline & pig & 6.453 & 0.822 & 5.792 & 1.291 & 0 & 4.868 & 1.569 & 3.755 & 1.479 & 6.151 & 1.099 & 2.151 & 0.928 \\
\hline & polar bear & 5.566 & 1.474 & 5.340 & 1.454 & 0 & 3.792 & 1.621 & 3.925 & 1.439 & 6.038 & 1.073 & 3.000 & 1.188 \\
\hline & polecat & 3.850 & 1.994 & 3.175 & 1.430 & 24.528 & 2.150 & 1.252 & 4.057 & 1.349 & 4.143 & 1.574 & 5.436 & 1.231 \\
\hline & pony & 5.962 & 1.037 & 5.642 & 1.415 & 0 & 4.283 & 1.691 & 3.906 & 1.418 & 6.151 & 1.026 & 2.755 & 1.159 \\
\hline & porcupine & 3.981 & 1.813 & 4.094 & 1.596 & 0 & 2.660 & 1.400 & 4.510 & 1.286 & 4.843 & 1.528 & 4.569 & 1.118 \\
\hline & porpoise & 3.714 & 1.732 & 3.776 & 1.490 & 7.547 & 2.592 & 1.353 & 3.978 & 1.256 & 4.609 & 1.612 & 5.170 & 1.257 \\
\hline & possum & 3.860 & 1.863 & 3.260 & 1.601 & 5.660 & 2.400 & 1.294 & 4.432 & 1.144 & 4.189 & 1.561 & 5.286 & 1.258 \\
\hline & puma & 4.472 & 1.867 & 4.170 & 1.503 & 0 & 2.830 & 1.297 & 4.096 & 1.404 & 4.961 & 1.509 & 4.509 & 1.368 \\
\hline & python & 4.000 & 1.641 & 4.509 & 1.449 & 0 & 2.792 & 1.364 & 3.170 & 1.312 & 5.321 & 1.283 & 4.151 & 1.133 \\
\hline & rabbit & 6.642 & 0.558 & 6.358 & 0.901 & 0 & 5.434 & 1.448 & 3.868 & 1.345 & 6.434 & 0.951 & 2.377 & 0.945 \\
\hline & raccoon & 4.396 & 1.790 & 4.094 & 1.690 & 0 & 2.755 & 1.453 & 4.038 & 1.267 & 5.058 & 1.474 & 4.151 & 1.262 \\
\hline & rat & 5.302 & 1.295 & 5.340 & 1.413 & 0 & 4.019 & 1.704 & 3.340 & 1.358 & 6.038 & 1.091 & 2.906 & 1.024 \\
\hline & rattlesnake & 4.057 & 1.726 & 4.472 & 1.588 & 0 & 2.755 & 1.440 & 3.585 & 1.447 & 5.189 & 1.455 & 4.264 & 1.041 \\
\hline & reindeer & 4.604 & 1.780 & 5.208 & 1.472 & 0 & 3.830 & 1.566 & 4.151 & 1.574 & 5.868 & 1.241 & 2.453 & 0.911 \\
\hline & rhinoceros & 5.434 & 1.337 & 5.057 & 1.336 & 0 & 3.189 & 1.494 & 4.365 & 1.221 & 5.769 & 1.165 & 3.365 & 1.138 \\
\hline & salamander & 3.158 & 1.586 & 3.132 & 1.379 & 28.302 & 2.263 & 1.131 & 4.156 & 1.298 & 3.813 & 1.447 & 5.389 & 1.225 \\
\hline & salmon & 3.679 & 1.752 & 5.434 & 1.323 & 0 & 4.509 & 1.489 & 3.673 & 1.339 & 5.340 & 1.493 & 3.868 & 0.941 \\
\hline & sea horse & 3.094 & 1.768 & 4.245 & 1.675 & 0 & 2.453 & 1.381 & 4.827 & 1.478 & 5.415 & 1.473 & 4.019 & 1.152 \\
\hline & sea lion & 4.269 & 1.561 & 4.346 & 1.520 & 1.887 & 2.712 & 1.419 & 3.941 & 1.287 & 5.216 & 1.346 & 3.882 & 1.160 \\
\hline & seal & 4.774 & 1.552 & 5.094 & 1.471 & 0 & 3.660 & 1.413 & 3.736 & 1.211 & 5.887 & 1.068 & 3.453 & 1.119 \\
\hline & shark & 4.404 & 1.695 & 5.154 & 1.392 & 0 & 3.731 & 1.805 & 3.865 & 1.237 & 6.115 & 1.078 & 3.057 & 1.008 \\
\hline & sheep & 6.472 & 0.775 & 6.264 & 1.077 & 0 & 5.596 & 1.404 & 3.509 & 1.705 & 6.377 & 1.213 & 2.000 & 0.855 \\
\hline & shrew & 4.292 & 1.675 & 3.750 & 1.644 & 9.434 & 2.542 & 1.220 & 3.667 & 1.225 & 4.333 & 1.610 & 4.625 & 1.142 \\
\hline & shrimp & 3.154 & 1.626 & 4.654 & 1.480 & 0 & 3.442 & 1.461 & 4.039 & 1.414 & 5.059 & 1.287 & 4.442 & 1.127 \\
\hline & skunk & 4.308 & 1.799 & 4.058 & 1.552 & 0 & 2.462 & 1.146 & 4.118 & 1.437 & 5.235 & 1.478 & 3.885 & 1.182 \\
\hline & sloth & 3.605 & 1.911 & 3.711 & 1.723 & 28.302 & 2.605 & 1.424 & 4.156 & 1.298 & 4.500 & 1.849 & 5.324 & 1.375 \\
\hline & snake & 5.173 & 1.581 & 5.577 & 1.363 & 0 & 3.942 & 1.809 & 3.038 & 1.495 & 6.365 & 0.908 & 2.673 & 1.098 \\
\hline & sole & 2.756 & 2.022 & 3.875 & 1.814 & 23.077 & 3.049 & 1.816 & 3.306 & 1.283 & 4.556 & 1.501 & 5.073 & 1.330 \\
\hline & squirrel & 5.585 & 1.151 & 5.623 & 1.259 & 0 & 4.792 & 1.573 & 4.226 & 1.310 & 6.340 & 0.807 & 2.849 & 1.081 \\
\hline & stoat & 4.292 & 1.810 & 3.875 & 1.579 & 9.434 & 2.583 & 1.235 & 3.783 & 1.263 & 4.261 & 1.692 & 4.660 & 1.221 \\
\hline & tapir & 3.267 & 1.751 & 2.867 & 1.407 & 71.698 & 1.929 & 0.829 & 4.786 & 1.051 & 4.167 & 1.528 & 6.333 & 0.816 \\
\hline & terrapin & 3.608 & 1.613 & 3.922 & 1.573 & 3.774 & 2.549 & 1.346 & 3.875 & 1.214 & 4.917 & 1.366 & 4.882 & 1.291 \\
\hline & tiger & 6.189 & 1.144 & 5.434 & 1.575 & 0 & 4.075 & 1.730 & 4.340 & 1.440 & 6.340 & 1.143 & 2.642 & 1.076 \\
\hline & toad & 4.208 & 1.691 & 4.962 & 1.506 & 0 & 3.415 & 1.379 & 3.868 & 1.532 & 5.623 & 1.213 & 3.170 & 1.014 \\
\hline & tortoise & 4.755 & 1.453 & 5.189 & 1.331 & 0 & 3.528 & 1.475 & 3.906 & 1.390 & 5.736 & 1.129 & 3.113 & 1.013 \\
\hline & trout & 3.075 & 1.838 & 5.208 & 1.261 & 0 & 3.868 & 1.545 & 3.472 & 1.381 & 5.283 & 1.321 & 3.943 & 1.064 \\
\hline
\end{tabular}


APPENDIX A (Continued)

\begin{tabular}{|c|c|c|c|c|c|c|c|c|c|c|c|c|c|c|}
\hline \multirow[b]{3}{*}{ Subcategory } & \multirow[b]{3}{*}{ Exemplar } & \multirow{2}{*}{\multicolumn{2}{|c|}{ Typicality }} & \multicolumn{3}{|c|}{ Familiarity } & \multirow{2}{*}{\multicolumn{2}{|c|}{ Frequency }} & \multirow{2}{*}{\multicolumn{2}{|c|}{$\begin{array}{c}\text { Visual } \\
\text { Complexity }\end{array}$}} & \multirow{2}{*}{\multicolumn{2}{|c|}{ Imageability }} & \multirow{2}{*}{\multicolumn{2}{|c|}{$\begin{array}{c}\text { Age of } \\
\text { Acquisition }\end{array}$}} \\
\hline & & & & & & Unknown & & & & & & & & \\
\hline & & $M$ & $S D$ & $M$ & $S D$ & & $M$ & $S D$ & $M$ & $\overline{S D}$ & $M$ & $S D$ & $M$ & $S D$ \\
\hline \multirow[t]{11}{*}{ Animals } & turtle & 4.547 & 1.539 & 4.868 & 1.415 & 0 & 3.302 & 1.462 & 4.057 & 1.336 & 5.642 & 1.415 & 3.566 & 0.991 \\
\hline & & 4.022 & 1.770 & 3.543 & 1.656 & 13.208 & 2.304 & 1.245 & 3.548 & 1.292 & 4.214 & 1.646 & 4.761 & 1.251 \\
\hline & & 3.863 & 1.613 & 3.569 & 1.591 & 3.774 & 251 & & 4.163 & & 4.419 & 1.384 & 4.980 & 1.334 \\
\hline & & 4.396 & 1.822 & 4.245 & 1. & 0 & 2.717 & 36 & 115 & 1.215 & 5.000 & 1.612 & 4.075 & 1.313 \\
\hline & warthog & 3.795 & 1.812 & 3.568 & 1.634 & 16.981 & 2.250 & 1.102 & 3.973 & 1.536 & 4.514 & 1.502 & 5.227 & 1.327 \\
\hline & weasel & 4.566 & 1.704 & 4.226 & 1.396 & 0 & 3.151 & 1.406 & 3.769 & 1.262 & 4.769 & 1.592 & 4.019 & 1.263 \\
\hline & & 4.736 & 1.643 & 5.038 & 1.454 & 0 & 3.792 & 1.691 & 3.623 & 1.471 & 5.943 & 1.117 & 3.094 & 1.079 \\
\hline & wildebeest & 4.417 & 1.889 & 3.833 & 1.667 & 7.692 & 2.646 & 1.537 & 4.409 & 1.419 & 4.705 & 1.679 & 5.333 & 1.358 \\
\hline & wol & 5.566 & 1.135 & 5.283 & 1.364 & 0 & 3.660 & 1.605 & 3.868 & 1.373 & 5.755 & 1.357 & 3.000 & 1.038 \\
\hline & wombat & 4.065 & 1.890 & 3.348 & 1.609 & 13.208 & 2.261 & 1.182 & 3.821 & 1.254 & 3.769 & 1.366 & 5.000 & 1.297 \\
\hline & zebra & 5.623 & 1.596 & 5.340 & 1.400 & 0 & 3.830 & 1.762 & 4.321 & 1.397 & 6.264 & 0.944 & 2.981 & 1.152 \\
\hline
\end{tabular}


APPENDIX B

Normative Ratings of Exemplars From the Animal Category From Older Adults

\begin{tabular}{|c|c|c|c|c|c|c|c|c|c|c|c|c|c|c|}
\hline \multirow[b]{3}{*}{ Subcategory } & \multirow[b]{3}{*}{ Exemplar } & \multirow{2}{*}{\multicolumn{2}{|c|}{ Typicality }} & \multicolumn{3}{|c|}{ Familiarity } & \multirow{2}{*}{\multicolumn{4}{|c|}{$\begin{array}{c}\text { Visual } \\
\text { Complexity }\end{array}$}} & \multirow{2}{*}{\multicolumn{2}{|c|}{ Imageability }} & \multirow{2}{*}{\multicolumn{2}{|c|}{$\begin{array}{c}\text { Age of } \\
\text { Acquisition }\end{array}$}} \\
\hline & & & & \multirow[b]{2}{*}{$M$} & \multirow[b]{2}{*}{$S D$} & Unknown & & & & & & & & \\
\hline & & $M$ & $S D$ & & & $(\%)$ & $M$ & $S D$ & $M$ & $S D$ & $M$ & $S D$ & $M$ & $S D$ \\
\hline Animals & aardvark & 3.694 & 2.026 & 2.257 & 1.221 & 32.692 & 1.714 & 0.825 & 3.857 & 1.380 & 3.893 & 1.618 & 6.774 & 0.717 \\
\hline & alligator & 4.942 & 1.614 & 3.942 & 1.776 & 3.704 & 2.725 & 1.234 & 4.327 & 1.593 & 5.490 & 1.666 & 5.519 & 1.435 \\
\hline & anteater & 4.109 & 1.969 & 2.867 & 1.486 & 15.094 & 2.067 & 0.939 & 3.933 & 1.629 & 4.630 & 1.717 & 6.442 & 0.959 \\
\hline & antelope & 5.462 & 1.421 & 4.500 & 1.603 & 1.887 & 2.808 & 1.344 & 4.346 & 1.399 & 5.635 & 1.221 & 5.712 & 1.304 \\
\hline & ape & 6.189 & 1.039 & 4.943 & 1.791 & 0 & 3.547 & 1.771 & 4.528 & 1.636 & 6.057 & 1.262 & 4.679 & 1.370 \\
\hline & armadillo & 4.560 & 1.950 & 3.220 & 1.502 & 7.407 & 2.080 & 0.986 & 4.468 & 1.530 & 5.170 & 1.672 & 6.510 & 0.869 \\
\hline & ass & 5.528 & 1.501 & 4.415 & 1.715 & 1.852 & 2.774 & 1.354 & 3.925 & 1.639 & 5.849 & 1.511 & 4.566 & 1.526 \\
\hline & baboon & 5.235 & 1.795 & 4.120 & 1.624 & 3.846 & 2.725 & 1.457 & 4.137 & 1.429 & 5.706 & 1.301 & 5.667 & 1.352 \\
\hline & badger & 5.189 & 1.532 & 4.196 & 1.588 & 1.923 & 2.840 & 1.376 & 4.115 & 1.580 & 5.673 & 1.248 & 5.442 & 1.378 \\
\hline & bat & 4.296 & 1.818 & 3.962 & 1.771 & 0 & 2.635 & 1.358 & 4.400 & 1.525 & 5.412 & 1.651 & 4.923 & 1.370 \\
\hline & bear & 6.226 & 1.086 & 5.132 & 1.665 & 0 & 3.585 & 1.737 & 4.038 & 1.675 & 6.453 & 1.066 & 3.434 & 1.623 \\
\hline & beaver & 4.906 & 1.757 & 4.075 & 1.828 & 1.852 & 2.547 & 1.218 & 4.189 & 1.606 & 5.396 & 1.446 & 5.491 & 1.409 \\
\hline & $\begin{array}{l}\text { bison } \\
\text { black }\end{array}$ & 5.019 & 1.623 & 3.868 & 1.665 & 1.852 & 2.308 & 1.130 & 4.019 & 1.565 & 5.736 & 1.375 & 6.132 & 1.177 \\
\hline & widow & 3.932 & 2.128 & 2.372 & 1.346 & 17.308 & 1.628 & 0.874 & 4.027 & 1.724 & 4.658 & 1.893 & 6.750 & 0.630 \\
\hline & buffalo & 5.288 & 1.775 & 4.019 & 1.639 & 1.887 & 2.404 & 1.089 & 4.365 & 1.572 & 5.692 & 1.322 & 5.588 & 1.219 \\
\hline & camel & 5.510 & 1.642 & 4.941 & 1.593 & 0 & 3.039 & 1.720 & 4.118 & 1.608 & 6.196 & 1.281 & 4.529 & 1.347 \\
\hline & cat & 6.815 & 0.585 & 6.630 & 0.938 & 0 & 6.315 & 1.130 & 4.222 & 1.880 & 6.722 & 0.596 & 2.222 & 1.208 \\
\hline & cheetah & 5.340 & 1.617 & 4.170 & 1.707 & 1.852 & 2.642 & 1.331 & 4.288 & 1.564 & 5.686 & 1.490 & 5.868 & 1.345 \\
\hline & chimpanzee & 5.981 & 1.232 & 4.811 & 1.688 & 1.852 & 3.264 & 1.643 & 4.500 & 1.515 & 6.000 & 1.103 & 4.788 & 1.319 \\
\hline & chinchilla & 4.583 & 1.796 & 3.563 & 1.821 & 11.111 & 2.447 & 1.248 & 3.800 & 1.632 & 4.800 & 1.779 & 6.553 & 0.951 \\
\hline & chipmunk & 4.458 & 1.624 & 3.255 & 1.496 & 7.843 & 2.340 & 1.069 & 4.043 & 1.488 & 4.660 & 1.659 & 6.711 & 0.589 \\
\hline & $\operatorname{cod}$ & 4.098 & 2.369 & 5.288 & 1.513 & 0 & 4.327 & 1.812 & 3.288 & 1.513 & 5.635 & 1.521 & 4.667 & 1.424 \\
\hline & cougar & 4.830 & 1.878 & 3.623 & 1.712 & 1.852 & 2.264 & 1.022 & 3.981 & 1.550 & 4.808 & 1.704 & 6.491 & 0.953 \\
\hline & cow & 6.852 & 0.408 & 6.537 & 0.905 & 0 & 5.685 & 1.588 & 4.204 & 1.857 & 6.698 & 0.932 & 2.604 & 1.321 \\
\hline & coyote & 4.480 & 1.752 & 3.080 & 1.748 & 5.660 & 2.180 & 1.101 & 3.681 & 1.643 & 4.553 & 1.767 & 6.313 & 1.151 \\
\hline & crab & 4.615 & 1.922 & 5.019 & 1.651 & 1.887 & 3.442 & 1.526 & 4.615 & 1.430 & 6.077 & 1.152 & 4.019 & 1.663 \\
\hline & crocodile & 5.167 & 1.463 & 4.407 & 1.775 & 0 & 2.796 & 1.534 & 4.434 & 1.587 & 6.130 & 1.198 & 4.611 & 1.485 \\
\hline & deer & 6.130 & 1.360 & 5.444 & 1.327 & 0 & 4.057 & 1.748 & 4.296 & 1.423 & 6.222 & 1.327 & 4.296 & 1.462 \\
\hline & dingo & 4.353 & 2.018 & 3.220 & 1.595 & 5.660 & 2.220 & 1.166 & 3.653 & 1.451 & 5.102 & 1.461 & 6.592 & 0.888 \\
\hline & $\operatorname{dog}$ & 6.981 & 0.139 & 6.750 & 0.711 & 0 & 6.667 & 0.864 & 4.365 & 1.910 & 6.538 & 1.163 & 2.423 & 1.513 \\
\hline & dolphin & 4.510 & 1.736 & 4.846 & 1.638 & 3.704 & 3.269 & 1.483 & 3.731 & 1.457 & 6.173 & 1.200 & 6.137 & 1.149 \\
\hline & $\begin{array}{l}\text { donkey } \\
\text { duck-billed }\end{array}$ & 6.019 & 1.236 & 5.370 & 1.483 & 0 & 3.463 & 1.587 & 3.963 & 1.822 & 6.296 & 1.110 & 3.315 & 1.241 \\
\hline & platypus & 3.600 & 2.093 & 3.065 & 1.769 & 13.208 & 1.978 & 1.011 & 4.244 & 1.464 & 4.778 & 1.731 & 6.304 & 0.986 \\
\hline & eel & 3.588 & 1.899 & 4.000 & 1.685 & 3.774 & 2.510 & 1.223 & 2.706 & 1.404 & 5.843 & 1.419 & 5.020 & 1.635 \\
\hline & elephant & 6.389 & 1.156 & 5.491 & 1.436 & 0 & 3.943 & 1.703 & 4.358 & 1.630 & 6.566 & 0.910 & 3.407 & 1.311 \\
\hline & elk & 5.000 & 1.744 & 3.673 & 1.560 & 7.547 & 2.271 & 1.125 & 4.271 & 1.333 & 5.020 & 1.714 & 6.224 & 1.246 \\
\hline & ferret & 4.852 & 1.687 & 3.963 & 1.625 & 0 & 2.481 & 1.314 & 3.796 & 1.653 & 5.167 & 1.489 & 5.759 & 1.317 \\
\hline & fox & 5.943 & 1.262 & 5.057 & 1.447 & 0 & 3.925 & 1.674 & 4.151 & 1.610 & 6.173 & 1.133 & 4.170 & 1.638 \\
\hline & frog & 5.113 & 1.928 & 5.415 & 1.562 & 1.852 & 3.604 & 1.736 & 4.434 & 1.538 & 6.245 & 1.125 & 3.604 & 1.349 \\
\hline & gazelle & 5.286 & 1.633 & 3.857 & 1.633 & 5.769 & 2.755 & 1.465 & 4.408 & 1.499 & 5.429 & 1.708 & 6.102 & 1.085 \\
\hline & gerbil & 4.692 & 1.799 & 3.961 & 1.843 & 1.923 & 2.667 & 1.291 & 3.720 & 1.565 & 4.940 & 1.583 & 6.667 & 0.841 \\
\hline & giraffe & 5.667 & 1.427 & 4.685 & 1.658 & 0 & 3.019 & 1.498 & 4.389 & 1.420 & 6.302 & 1.295 & 4.019 & 1.460 \\
\hline & gnu & 3.953 & 2.035 & 2.818 & 1.674 & 18.519 & 2.091 & 1.158 & 3.923 & 1.612 & 4.150 & 1.748 & 6.682 & 0.601 \\
\hline & goat & 6.096 & 1.142 & 5.308 & 1.408 & 0 & 3.788 & 1.719 & 4.115 & 1.580 & 6.077 & 1.341 & 3.769 & 1.463 \\
\hline & goldfish & 4.096 & 2.135 & 5.192 & 1.633 & 1.887 & 3.627 & 1.732 & 3.667 & 1.545 & 6.020 & 1.364 & 3.788 & 1.419 \\
\hline & gopher & 3.919 & 1.801 & 2.162 & 1.143 & 30.189 & 1.757 & 0.925 & 3.563 & 1.703 & 3.625 & 1.773 & 6.909 & 0.292 \\
\hline & gorilla & 6.019 & 1.394 & 4.830 & 1.590 & 0 & 3.396 & 1.621 & 4.463 & 1.622 & 6.259 & 1.031 & 4.852 & 1.323 \\
\hline & guinea pig & 4.923 & 1.690 & 4.275 & 1.650 & 3.774 & 2.820 & 1.335 & 3.784 & 1.540 & 5.373 & 1.523 & 5.863 & 1.167 \\
\hline & haddock & 4.373 & 2.408 & 5.902 & 1.552 & 1.923 & 5.569 & 1.526 & 3.647 & 1.695 & 6.000 & 1.371 & 4.490 & 1.543 \\
\hline & hamster & 5.170 & 1.626 & 4.472 & 1.782 & 1.852 & 3.340 & 1.675 & 3.712 & 1.333 & 5.577 & 1.473 & 6.462 & 0.979 \\
\hline & hare & 5.615 & 1.416 & 5.135 & 1.547 & 0 & 3.308 & 1.675 & 4.212 & 1.661 & 5.942 & 1.195 & 4.385 & 1.484 \\
\hline & hedgehog & 5.537 & 1.526 & 5.130 & 1.542 & 0 & 3.302 & 1.526 & 4.278 & 1.618 & 6.241 & 1.212 & 4.537 & 1.634 \\
\hline & $\begin{array}{l}\text { herring } \\
\text { hippo- }\end{array}$ & 3.925 & 2.336 & 5.667 & 1.427 & 0 & 4.611 & 1.878 & 3.491 & 1.601 & 6.019 & 1.248 & 4.370 & 1.629 \\
\hline & potamus & 5.623 & 1.496 & 4.365 & 1.772 & 1.887 & 2.962 & 1.544 & 4.264 & 1.723 & 5.923 & 1.341 & 4.811 & 1.507 \\
\hline & horse & 6.852 & 0.452 & 6.444 & 1.058 & 0 & 5.352 & 1.650 & 4.537 & 1.734 & 6.717 & 0.841 & 2.679 & 1.451 \\
\hline & hyena & 4.981 & 1.792 & 3.885 & 1.653 & 1.887 & 2.635 & 1.103 & 4.080 & 1.455 & 5.260 & 1.614 & 5.843 & 1.189 \\
\hline & iguana & 3.896 & 1.927 & 3.208 & 1.798 & 11.111 & 2.167 & 1.018 & 4.711 & 1.502 & 4.844 & 1.678 & 6.909 & 0.291 \\
\hline & impala & 4.356 & 1.932 & 3.356 & 1.554 & 13.462 & 2.178 & 0.984 & 4.023 & 1.456 & 4.953 & 1.632 & 6.814 & 0.664 \\
\hline & jackal & 4.898 & 1.794 & 3.816 & 1.481 & 5.769 & 2.510 & 1.175 & 3.917 & 1.569 & 4.813 & 1.633 & 6.082 & 1.320 \\
\hline & jaguar & 5.377 & 1.496 & 4.075 & 1.674 & 1.852 & 2.717 & 1.306 & 4.075 & 1.591 & 5.604 & 1.485 & 6.057 & 1.117 \\
\hline & jellyfish & 3.717 & 2.060 & 4.962 & 1.675 & 0 & 2.774 & 1.281 & 4.000 & 1.847 & 5.792 & 1.668 & 4.075 & 1.466 \\
\hline & kangaroo & 5.463 & 1.610 & 4.704 & 1.849 & 0 & 3.019 & 1.642 & 4.463 & 1.488 & 6.222 & 1.298 & 4.906 & 1.431 \\
\hline & koala & 5.208 & 1.680 & 4.472 & 1.867 & 0 & 2.849 & 1.336 & 4.151 & 1.486 & 5.811 & 1.345 & 6.423 & 1.144 \\
\hline
\end{tabular}


APPENDIX B (Continued)

\begin{tabular}{|c|c|c|c|c|c|c|c|c|c|c|c|c|c|c|}
\hline \multirow[b]{3}{*}{ Subcategory } & \multirow[b]{3}{*}{ Exemplar } & \multirow{2}{*}{\multicolumn{2}{|c|}{ Typicality }} & \multicolumn{3}{|c|}{ Familiarity } & \multirow{2}{*}{\multicolumn{2}{|c|}{ Frequency }} & \multirow{2}{*}{\multicolumn{2}{|c|}{$\begin{array}{c}\text { Visual } \\
\text { Complexity }\end{array}$}} & \multirow{2}{*}{\multicolumn{2}{|c|}{ Imageability }} & $\mathrm{Ag}$ & of \\
\hline & & & & & & Unk & & & & & & & Acqu & sition \\
\hline & & $M$ & $S D$ & $M$ & $S D$ & $(\%)$ & $M$ & $S D$ & $M$ & $S D$ & $M$ & $S D$ & $M$ & $S D$ \\
\hline Animals & lemming & 4.292 & 1.890 & 2.979 & 1.581 & 11.321 & 2.170 & 1.185 & 3.707 & 1.537 & 4.341 & 1.477 & 6.652 & 0.849 \\
\hline & lemur & 4.676 & 2.028 & 2.946 & 1.763 & 28.846 & 1.811 & 0.877 & 3.972 & 1.383 & 4.472 & 1.812 & 6.816 & 0.457 \\
\hline & leopard & 5.736 & 1.546 & 4.623 & 1.667 & 0 & 2.981 & 1.474 & 4.623 & 1.484 & 6.170 & 1.236 & 4.755 & 1.413 \\
\hline & lion & 6.611 & 0.685 & 5.259 & 1.532 & 0 & 3.755 & 1.568 & 4.389 & 1.595 & 6.444 & 1.058 & 3.434 & 1.217 \\
\hline & lizard & 4.604 & 1.758 & 4.264 & 1.571 & 1.852 & 2.717 & 1.166 & 4.396 & 1.405 & 5.792 & 1.276 & 5.769 & 1.337 \\
\hline & llama & 4.830 & 1.729 & 4.000 & 1.581 & 1.852 & 2.358 & 1.002 & 4.151 & 1.499 & 5.491 & 1.409 & 6.208 & 1.199 \\
\hline & lobster & 4.020 & 2.015 & 4.431 & 1.628 & 3.774 & 2.922 & 1.412 & 4.745 & 1.426 & 5.745 & 1.324 & 5.720 & 1.471 \\
\hline & lynx & 4.765 & 1.704 & 3.320 & 1.377 & 5.660 & 2.360 & 1.005 & 4.408 & 1.398 & 4.958 & 1.725 & 6.320 & 1.039 \\
\hline & meerkat & 3.714 & 2.122 & 2.529 & 1.637 & 33.333 & 1.941 & 0.851 & 3.700 & 1.745 & 4.700 & 2.120 & 6.968 & 0.180 \\
\hline & $\operatorname{mink}$ & 4.500 & 1.755 & 3.500 & 1.627 & 0 & 2.365 & 1.284 & 3.780 & 1.542 & 4.918 & 1.847 & 6.608 & 0.750 \\
\hline & mole & 5.000 & 1.544 & 4.019 & 1.565 & 1.887 & 2.654 & 1.312 & 3.615 & 1.510 & 5.404 & 1.432 & 4.904 & 1.432 \\
\hline & mongoose & 4.220 & 1.866 & 2.938 & 1.590 & 7.692 & 1.875 & 0.815 & 3.721 & 1.548 & 4.395 & 1.917 & 6.313 & 1.075 \\
\hline & monkey & 6.226 & 1.068 & 5.660 & 1.628 & 0 & 3.887 & 1.888 & 4.302 & 1.475 & 6.377 & 1.023 & 3.358 & 1.302 \\
\hline & moose & 5.019 & 1.709 & 3.808 & 1.704 & 3.704 & 2.250 & 1.118 & 4.212 & 1.625 & 5.365 & 1.597 & 6.196 & 1.132 \\
\hline & mouse & 5.943 & 1.420 & 5.642 & 1.469 & 0 & 3.642 & 1.798 & 3.660 & 1.720 & 6.472 & 1.103 & 3.170 & 1.411 \\
\hline & mule & 5.283 & 1.446 & 4.547 & 1.612 & 1.852 & 2.792 & 1.166 & 3.868 & 1.630 & 5.755 & 1.426 & 5.308 & 1.422 \\
\hline & muskrat & 3.595 & 1.822 & 2.683 & 1.507 & 22.642 & 1.675 & 0.829 & 3.769 & 1.677 & 3.875 & 1.539 & 6.659 & 0.656 \\
\hline & newt & 3.979 & 1.896 & 3.646 & 1.720 & 9.434 & 2.271 & 1.144 & 3.723 & 1.514 & 4.702 & 1.829 & 5.542 & 1.429 \\
\hline & ocelot & 4.673 & 1.962 & 3.340 & 1.791 & 7.407 & 2.306 & 1.294 & 4.170 & 1.565 & 5.000 & 1.714 & 6.667 & 0.663 \\
\hline & octopus & 3.843 & 1.922 & 4.058 & 1.765 & 1.887 & 2.627 & 1.428 & 4.588 & 1.551 & 6.135 & 1.284 & 5.154 & 1.289 \\
\hline & orangutan & 5.220 & 1.607 & 3.920 & 1.550 & 3.846 & 2.700 & 1.266 & 4.673 & 1.612 & 5.857 & 1.369 & 6.286 & 1.173 \\
\hline & otter & 5.264 & 1.508 & 4.283 & 1.714 & 1.852 & 2.830 & 1.383 & 4.019 & 1.474 & 5.679 & 1.283 & 5.509 & 1.436 \\
\hline & ox & 5.296 & 1.723 & 4.241 & 1.780 & 0 & 2.870 & 1.649 & 4.056 & 1.630 & 5.537 & 1.563 & 4.792 & 1.691 \\
\hline & panda & 5.377 & 1.678 & 4.660 & 1.663 & 1.852 & 3.302 & 1.551 & 4.075 & 1.492 & 6.038 & 1.343 & 5.830 & 1.638 \\
\hline & panther & 5.462 & 1.553 & 4.000 & 1.669 & 3.704 & 2.577 & 1.289 & 4.231 & 1.436 & 5.731 & 1.457 & 5.750 & 1.297 \\
\hline & pig & 6.630 & 0.653 & 6.037 & 1.303 & 0 & 4.566 & 2.005 & 3.889 & 1.645 & 6.463 & 0.985 & 3.056 & 1.352 \\
\hline & polar bear & 5.778 & 1.369 & 5.074 & 1.576 & 0 & 3.167 & 1.437 & 3.815 & 1.518 & 6.426 & 0.983 & 4.415 & 1.460 \\
\hline & polecat & 4.327 & 1.801 & 2.804 & 1.497 & 3.774 & 1.941 & 0.947 & 3.680 & 1.671 & 4.400 & 1.654 & 6.620 & 0.830 \\
\hline & pony & 6.340 & 0.999 & 5.566 & 1.575 & 0 & 4.226 & 1.660 & 4.019 & 1.704 & 6.392 & 1.168 & 3.434 & 1.474 \\
\hline & porcupine & 4.510 & 1.880 & 3.588 & 1.499 & 5.556 & 2.216 & 0.986 & 4.647 & 1.440 & 5.804 & 1.429 & 5.520 & 1.389 \\
\hline & porpoise & 4.500 & 1.764 & 4.200 & 1.525 & 3.846 & 3.140 & 1.414 & 4.060 & 1.449 & 5.640 & 1.467 & 5.857 & 1.339 \\
\hline & possum & 4.149 & 2.126 & 2.848 & 1.445 & 11.538 & 1.957 & 0.918 & 3.930 & 1.549 & 4.349 & 1.717 & 6.711 & 0.549 \\
\hline & puma & 5.226 & 1.671 & 3.904 & 1.871 & 1.887 & 2.500 & 1.291 & 4.039 & 1.455 & 5.481 & 1.515 & 5.865 & 1.314 \\
\hline & python & 4.321 & 2.073 & 3.685 & 1.820 & 0 & 2.315 & 1.371 & 3.611 & 1.522 & 5.556 & 1.475 & 5.870 & 1.117 \\
\hline & rabbit & 6.385 & 1.123 & 6.192 & 1.121 & 0 & 4.765 & 1.668 & 4.058 & 1.638 & 6.558 & 0.978 & 3.196 & 1.536 \\
\hline & raccoon & 4.528 & 1.877 & 3.080 & 1.510 & 1.961 & 2.137 & 1.059 & 4.146 & 1.487 & 4.750 & 1.804 & 6.260 & 1.192 \\
\hline & rat & 5.698 & 1.462 & 4.604 & 1.822 & 1.852 & 3.132 & 1.594 & 3.654 & 1.494 & 6.077 & 1.186 & 4.151 & 1.598 \\
\hline & rattlesnake & 4.216 & 2.003 & 3.265 & 1.741 & 5.769 & 2.204 & 1.190 & 3.660 & 1.636 & 5.163 & 1.637 & 5.920 & 1.368 \\
\hline & reindeer & 5.537 & 1.551 & 5.074 & 1.515 & 0 & 3.370 & 1.629 & 4.426 & 1.368 & 6.189 & 1.178 & 3.538 & 1.686 \\
\hline & rhinoceros & 5.585 & 1.420 & 4.377 & 1.757 & 1.852 & 2.849 & 1.446 & 4.547 & 1.514 & 6.075 & 1.299 & 4.925 & 1.412 \\
\hline & salamander & 3.690 & 1.880 & 2.750 & 1.565 & 21.569 & 1.800 & 0.853 & 3.921 & 1.531 & 4.526 & 1.751 & 6.675 & 0.797 \\
\hline & salmon & 4.135 & 2.284 & 5.654 & 1.595 & 1.887 & 4.863 & 1.778 & 3.712 & 1.661 & 6.250 & 1.266 & 4.980 & 1.581 \\
\hline & sea horse & 3.383 & 1.848 & 3.468 & 1.613 & 11.321 & 2.130 & 1.002 & 4.222 & 1.330 & 5.532 & 1.600 & 6.128 & 1.244 \\
\hline & sea lion & 4.577 & 1.775 & 4.058 & 1.830 & 3.704 & 2.673 & 1.396 & 3.725 & 1.457 & 5.569 & 1.578 & 5.673 & 1.478 \\
\hline & seal & 5.269 & 1.573 & 5.000 & 1.455 & 0 & 3.596 & 1.512 & 3.692 & 1.603 & 6.327 & 0.985 & 4.863 & 1.442 \\
\hline & shark & 4.196 & 1.980 & 4.333 & 1.705 & 3.774 & 2.980 & 1.703 & 3.686 & 1.490 & 5.980 & 1.319 & 5.039 & 1.442 \\
\hline & sheep & 6.755 & 0.585 & 6.491 & 1.012 & 0 & 5.585 & 1.610 & 4.283 & 1.610 & 6.623 & 0.882 & 3.000 & 1.581 \\
\hline & shrew & 4.660 & 1.857 & 3.326 & 1.739 & 13.208 & 2.304 & 1.227 & 3.444 & 1.439 & 4.911 & 1.717 & 6.261 & 1.063 \\
\hline & shrimp & 3.840 & 2.024 & 4.660 & 1.533 & 5.660 & 3.460 & 1.528 & 4.640 & 1.699 & 5.540 & 1.581 & 5.680 & 1.720 \\
\hline & skunk & 4.283 & 2.004 & 3.115 & 1.592 & 1.887 & 2.038 & 0.907 & 3.700 & 1.657 & 5.100 & 1.764 & 5.804 & 1.281 \\
\hline & sloth & 4.159 & 1.817 & 2.907 & 1.659 & 18.868 & 1.930 & 1.033 & 3.683 & 1.556 & 4.610 & 1.856 & 6.625 & 0.628 \\
\hline & snake & 4.887 & 1.804 & 4.264 & 1.862 & 1.852 & 2.925 & 1.479 & 3.377 & 1.608 & 6.245 & 0.998 & 4.115 & 1.247 \\
\hline & sole & 3.696 & 2.318 & 5.522 & 1.588 & 9.804 & 4.609 & 1.653 & 3.356 & 1.654 & 6.045 & 1.056 & 5.348 & 1.523 \\
\hline & squirrel & 6.019 & 1.339 & 5.852 & 1.338 & 0 & 4.685 & 1.820 & 4.226 & 1.683 & 6.340 & 1.073 & 4.204 & 1.583 \\
\hline & stoat & 5.038 & 1.581 & 4.170 & 1.695 & 1.852 & 2.415 & 1.134 & 3.706 & 1.514 & 5.173 & 1.630 & 5.500 & 1.528 \\
\hline & tapir & 4.075 & 1.900 & 2.897 & 1.373 & 26.415 & 2.000 & 1.000 & 4.000 & 1.242 & 4.583 & 1.730 & 6.842 & 0.370 \\
\hline & terrapin & 4.136 & 1.984 & 3.558 & 1.563 & 15.686 & 2.372 & 1.310 & 3.643 & 1.605 & 5.071 & 2.029 & 6.674 & 0.715 \\
\hline & tiger & 6.333 & 1.009 & 5.130 & 1.843 & 0 & 3.519 & 1.850 & 4.556 & 1.586 & 6.426 & 1.092 & 3.778 & 1.513 \\
\hline & toad & 4.736 & 1.619 & 4.358 & 1.558 & 0 & 2.717 & 1.292 & 4.283 & 1.634 & 5.660 & 1.372 & 4.585 & 1.365 \\
\hline & tortoise & 5.302 & 1.436 & 4.887 & 1.540 & 1.852 & 3.113 & 1.382 & 3.925 & 1.299 & 6.245 & 1.108 & 4.189 & 1.442 \\
\hline & trout & 3.900 & 2.323 & 5.306 & 1.517 & 0 & 4.265 & 1.741 & 3.796 & 1.500 & 6.061 & 1.215 & 5.383 & 1.328 \\
\hline & turtle & 4.453 & 1.760 & 3.868 & 1.732 & 1.852 & 2.679 & 1.298 & 4.132 & 1.557 & 5.415 & 1.622 & 6.000 & 1.160 \\
\hline & vole & 4.784 & 1.724 & 3.840 & 1.658 & 5.660 & 2.420 & 1.326 & 3.375 & 1.525 & 4.854 & 1.688 & 5.940 & 1.168 \\
\hline & wallaby & 4.635 & 1.727 & 3.712 & 1.673 & 3.704 & 2.327 & 1.200 & 4.327 & 1.410 & 5.451 & 1.540 & 6.462 & 0.874 \\
\hline & walrus & 4.547 & 1.671 & 3.868 & 1.699 & 0 & 2.604 & 1.261 & 4.346 & 1.312 & 5.717 & 1.306 & 5.302 & 1.265 \\
\hline & warthog & 4.130 & 1.746 & 2.848 & 1.605 & 13.208 & 1.957 & 0.868 & 3.953 & 1.447 & 4.614 & 1.646 & 6.909 & 0.291 \\
\hline
\end{tabular}


APPENDIX B (Continued)

\begin{tabular}{|c|c|c|c|c|c|c|c|c|c|c|c|c|c|c|}
\hline \multirow[b]{2}{*}{ Subcategory } & \multirow[b]{2}{*}{ Exemplar } & \multicolumn{2}{|c|}{ Typicality } & \multicolumn{3}{|c|}{ Familiarity } & \multicolumn{2}{|c|}{ Frequency } & \multicolumn{2}{|c|}{$\begin{array}{c}\text { Visual } \\
\text { Complexity }\end{array}$} & \multicolumn{2}{|c|}{ Imageability } & \multicolumn{2}{|c|}{$\begin{array}{c}\text { Age of } \\
\text { Acquisition }\end{array}$} \\
\hline & & $M$ & $S D$ & $M$ & $S D$ & $(\%)$ & $M$ & $S D$ & $M$ & $S D$ & $M$ & $S D$ & $M$ & $S D$ \\
\hline \multirow[t]{6}{*}{ Animals } & weasel & 5.212 & 1.576 & 3.863 & 1.625 & 3.774 & 2.725 & 1.313 & 3.900 & 1.474 & 5.265 & 1.565 & 5.200 & 1.443 \\
\hline & whale & 4.981 & 1.766 & 5.000 & 1.738 & 1.887 & 3.154 & 1.661 & 3.596 & 1.445 & 6.275 & 1.185 & 4.577 & 1.419 \\
\hline & wildebeest & 4.714 & 1.893 & 3.367 & 1.716 & 9.259 & 2.306 & 1.245 & 4.042 & 1.543 & 5.188 & 1.394 & 6.542 & 0.922 \\
\hline & wolf & 5.889 & 1.423 & 4.500 & 1.645 & 0 & 3.056 & 1.522 & 4.093 & 1.569 & 6.000 & 1.099 & 3.755 & 1.518 \\
\hline & wombat & 4.095 & 1.985 & 2.500 & 1.550 & 20.755 & 1.857 & 0.952 & 3.882 & 1.472 & 4.343 & 1.814 & 6.950 & 0.221 \\
\hline & zebra & 5.566 & 1.647 & 4.585 & 1.658 & 0 & 3.000 & 1.400 & 4.283 & 1.498 & 6.226 & 1.310 & 4.442 & 1.461 \\
\hline
\end{tabular}

(Manuscript received May 10, 2004;

revision accepted for publication September 21, 2004.) 